\title{
Resistance and Tolerance to Root Herbivory in Maize Were Mediated by Domestication, Spread, and Breeding
}

\author{
Ana A. Fontes-Pueblat ${ }^{\dagger}$ and Julio S. Bernal* \\ Department of Entomology, Texas A\&M University, College Station, TX, United States
}

\section{OPEN ACCESS}

Edited by:

Marcello Mastrorilli,

Council for Agricultural Research

and Economics, Italy

Reviewed by:

Magda Pál,

Agricultural Institute, Centre for Agricultural Research, Hungarian

Academy of Sciences, Hungary Juan Núñez-Farfán,

National Autonomous University of Mexico, Mexico

*Correspondence: Julio S. Bernal

julioberna/@tamu.edu

${ }^{\dagger}$ Present address:

Ana A. Fontes-Puebla, Instituto Nacional de Investigaciones Forestales, Agrícolas y Pecuarias:

Campo Experimental Costa

de Hermosillo, Centro de Investigación Regional del

Noroeste, Hermosillo, Mexico

Specialty section:

This article was submitted to Plant Breeding,

a section of the journal

Frontiers in Plant Science

Received: 27 September 2019

Accepted: 12 February 2020

Published: 27 February 2020

Citation:

Fontes-Puebla AA and Bernal JS (2020) Resistance and Tolerance to Root Herbivory in Maize Were Mediated by Domestication, Spread, and Breeding.

Front. Plant Sci. 11:223. doi: $10.3389 / \mathrm{fp} / \mathrm{s} .2020 .00223$
Plants may defend against herbivory and disease through various means. Plant defensive strategies against herbivores include resistance and tolerance, which may have metabolic costs that affect plant growth and reproduction. Thus, expression of these strategies may be mediated by a variety of factors, such as resource availability, herbivory pressure, and plant genetic variation, among others. Additionally, artificial selection by farmers and systematic breeding by scientists may mediate the expression of resistance and tolerance in crop plants. In this study, we tested whether maize defense against Western corn rootworm (WCR) was mediated by the crop's domestication, spread, and modern breeding. We expected to find a trend of decreasing resistance to WCR with maize domestication, spread, and breeding, and a trend of increasing tolerance with decreasing resistance. To test our expectations, we compared resistance and tolerance among four Zea plants spanning those processes: Balsas teosinte, Mexican landrace maize, US landrace maize, and US inbred maize. We measured the performance of WCR larvae as a proxy for plant resistance, and plant growth as affected by WCR feeding as a proxy for plant tolerance. Our results showed that domestication and spread decreased maize resistance to WCR, as expected, whereas breeding increased maize resistance to WCR, contrary to expected. Our results also showed that maize resistance and tolerance to WCR are negatively correlated, as expected. We discussed our findings in relation to ecological-evolutionary hypotheses seeking to explain defense strategy evolution in the contexts of plant resistance-productivity trade-offs, plant tolerance-resistance trade-offs, and varying resource availability vis-à-vis plant physiological stress and herbivory pressure. Finally, we suggested that defense strategy evolution in maize, from domestication to the present, is predicted by those ecological-evolutionary hypotheses.

Keywords: plant defense, Zea mays, Balsas teosinte, maize landraces, maize inbred lines, Diabrotica virgifera virgifera, optimal defense hypotheses, agricultural intensification

\section{INTRODUCTION}

Though sessile, plants are not defenseless organisms incapable of escaping their enemies, and generally employ various means for defending themselves against herbivory and disease. When directed against herbivory, such defensive means include physical and chemical defenses, the ability to manipulate primary metabolite allocation to reduce herbivore fitness, and tolerance, 
which are important mediators of plant reproductive success (Zhou et al., 2015; Zust and Agrawal, 2017). Broadly, plant defensive strategies include resistance and tolerance. Resistance relies on direct (physical and chemical) and indirect (e.g., natural enemies, phenology) defenses, and implies a negative effect on herbivores, while tolerance involves compensatory growth, increased photosynthesis, and other responses that allow plants to reproduce, without a negative effect on herbivores (Painter, 1951; Strauss and Agrawal, 1999; Boege and Marquis, 2005; Schoonhoven et al., 2005; Stout, 2013). Tolerance is relevant to both seedling and mature plants. Seedling plants under intense herbivory may be injured to the extent that they are incapable of reproducing or do not reach the reproductive stage, while mature plants under intense herbivory typically reproduce, even if at a lower level. Thus, compensation of tissue lost to herbivory may be a good proxy for tolerance in plant seedlings (Pujol et al., 2005; Barton and Hanley, 2013; Chinchilla-Ramírez et al., 2017). Overall, plant investment in defense seems to depend on resource availability, herbivore pressure, and genetic diversity (Hahn and Maron, 2016; Zust and Agrawal, 2017).

Whether below- or aboveground, defense against herbivores may be costly to both wild and cultivated plants. Generally, limited metabolic resources are distributed among multiple, competing processes, including defense (e.g., resistance) and productivity (i.e., growth and reproduction). Defenses against herbivores may be constitutive, which are continuously present, or induced, which are summoned in response to herbivory. Subjected to herbivory, plants may allocate resources to defense responses accordingly, while other processes, such as reproduction (e.g., production of flowers, fruits, seeds), may be allocated fewer resources (Bazzaz et al., 1987; Rodriguez-Saona et al., 2011; Zust and Agrawal, 2017). However, in cultivated plants more resources tend to be allocated toward productivity than defense. For example, breeding for productivity and quality compromised defenses against herbivores in cranberries, so that herbivore performance was enhanced and constitutive and induced defenses were reduced on domesticated compared to wild cranberries (Rodriguez-Saona et al., 2011). Also, in a study on Zea L. plants, maize wild relatives (Zea mays sspp.) were found to be better defended against herbivores, but had lower productivity, compared to modern cultivars of maize (Zea mays mays L.), which were poorly defended and had high productivity (Rosenthal and Dirzo, 1997). Interestingly, landrace maize, a form intermediate between maize wild relatives and modern maizes, showed intermediate defense and productivity. Overall, the study's results supported a hypothesis positing that herbivore resistance in maize decreased with domestication and improvement for yield (Rosenthal and Dirzo, 1997).

Domestication, spread, and breeding are processes that can mediate crop evolution, including herbivore defense evolution. Accordingly, domestication modified interactions between crops and insects so that they differ substantially from those between crop wild ancestors and their herbivores (Macfadyen and Bohan, 2010; Chen et al., 2015a; Wang et al., 2018). For instance, following the initial domestication of maize ca. 9000 years before present (YBP) (Matsuoka et al., 2002), the sap-sucking herbivore Dalbulus maidis (Delong and Wolcott) became a pest as the crop's defenses were weakened and as its distribution expanded from the Mexican subtropical lowlands to the temperate highlands and beyond (Nault, 1990; Medina et al., 2012; Bernal et al., 2017). As crops spread, they commonly face novel environmental variables, which may reshape plant-insect interactions (Baker, 1972; Erb et al., 2011; Meyer et al., 2012; Chen, 2016; Turcotte et al., 2017). Indeed, diverging climatic conditions, less competition, genetic drift associated with dispersal, among other variables, have been shown to produce changes in herbivory resistance in a variety of plants and crops (Rasmann et al., 2005; Zangerl and Berenbaum, 2005; Agrawal et al., 2012; Züst et al., 2012). Systematic breeding, along with geographical spread, also affects crop traits, including herbivore defenses. For example, maize underwent natural and artificial selection as it spread into new environments following its domestication (van Heerwaarden et al., 2012; Swarts et al., 2017; Kistler et al., 2018), and was subjected to systematic artificial selection (i.e., breeding) mainly for yield when agriculture was intensified in the 20th century (Troyer, 1999; Whitehead et al., 2017). Such selection shaped maize's herbivore defenses (Bellota et al., 2013; Dávila-Flores et al., 2013; de Lange et al., 2014; Maag et al., 2015; ChinchillaRamírez et al., 2017). Moreover, enhanced plant growth in the face of novel herbivory pressure may lead to tolerance evolution, as posited under the resource availability hypothesis, which predicts that fast-growing plants in resource-rich environments, such as crop plants, may be selected to favor herbivory tolerance, at the expense of resistance (Rosenthal and Dirzo, 1997; Zou et al., 2007; Agrawal et al., 2010).

Crop plants can become hosts for herbivores as a consequence of domestication, spread to new environments, and breeding for high yield, as noted previously (Chen et al., 2015a; Chen, 2016; Chen and Schoville, 2018). After maize's spread from the central Mexican highlands to North America, the oligophagous, root-chewing insect Western corn rootworm (WCR) (Diabrotica virgifera virgifera Le Conte) shifted to maize from an unknown ancestral Poaceae host to later become a pest (Lombaert et al., 2017). WCR likely spread with maize from northern Mexico to southwestern United States (ca. $1500 \mathrm{CE}$ ) as maize became a significant crop and part of the Native American diet (Merrill et al., 2009; da Fonseca et al., 2015; Lombaert et al., 2017; Smith et al., 2017). WCR prefers maize over other hosts, which may be due to the crop plant's comparatively weakened resistance against herbivory and greater nutritional value (de Lange et al., 2014; Bernal and Medina, 2018). Additionally, maize tolerance to WCR may have evolved as the crop faced less competition and nonnative herbivory after its spread (Buckler and Stevens, 2006; Hahn and Maron, 2016; Robert et al., 2017). Currently, WCR is found in northern Mexico, USA, and Europe (Branson and Krysan, 1981; Gerdes et al., 1993; Gray et al., 2009). The economic damage that this herbivore can cause varies, e.g., economic losses attributed to WCR may exceed US $\$ 1 B$ yearly in the United States (Gray et al., 2009), while in Europe they are estimated at $€ 472$ million per year (Wesseler and Fall, 2010).

Trade-offs between productivity and herbivore resistance, and between herbivore resistance and tolerance are at the base of hypotheses positing that with plant domestication and improvement for yield a crop's resistance will suffer compared 
to that of its wild ancestor, and that tolerance increases as resistance decreases (Hahn and Maron, 2016). Indeed, prior studies comparing the defense responses of maize wild ancestors and maize exposed to different herbivores showed resistance deescalations with domestication, spread, and breeding (Bellota et al., 2013; Szczepaniec et al., 2013; Bernal et al., 2015; Maag et al., 2015; Chinchilla-Ramírez et al., 2017), as well as increasing tolerance with spread (Zou et al., 2007). In this study, we tested whether maize defense against WCR was mediated by the crop's domestication, spread, and breeding. To that end, we compared resistance and tolerance among four Zea plant types spanning those processes: Balsas teosinte (Zea mays L. spp. parviglumis Iltis and Doebley), Mexican maize landraces, United States maize landraces, and United States maize breeding lines. The effects of domestication were assessed by comparing resistance and tolerance levels between Balsas teosintes and Mexican maize landraces; the effects of northward spread by comparing between Mexican landraces and US landraces, and; the effects of breeding by comparing between US landraces and US inbred lines. Specifically, we measured (i) performance of WCR larvae as a proxy for resistance, and (ii) plant growth as affected by WCR feeding as a proxy for tolerance. Overall, we expected to find decreasing resistance to WCR with maize domestication, spread and breeding, and increasing tolerance with decreasing resistance. We discussed our results in the context of plant resistance and tolerance evolution, as mediated by artificial and natural selection, geographical spread, and systematic breeding. Specifically, we discussed our findings in relation to ecological-evolutionary hypotheses seeking to explain defense strategy evolution in the contexts of plant resistanceproductivity trade-offs, plant tolerance-resistance trade-offs, and varying resource availability vis-à-vis plant physiological stress and herbivory pressure.

\section{RESULTS}

\section{Plant Resistance}

Through MANOVA we assessed whether insect and plant performances were affected by plant type (Figure 1). The analysis revealed a significant multivariate effect on both plant type (Wilks' $\lambda=0.365, P<0.001$ ) and accession nested within plant type $(\lambda=0.361, P=0.037)$. A priori contrasts between plant types showed significant differences between Balsas teosintes and Mexican landraces $\left(F_{7,69}=4.489, P<0.001\right)$ (i.e., a domestication effect) as well as for Mexican landraces and US landraces $\left(F_{7,69}=2.643, P=0.017\right)$ (i.e., a geographical spread effect), but not between US landraces and US inbred lines $\left(F_{7,69}=1.894, P=0.083\right)$ (i.e., a non-significant breeding effect). The vertical axis in the canonical plot explained $82 \%$ of the variation, with root $(r=0.814, P<0.001)$ and foliar $(r=0.766$, $P<0.001$ ) weights as the variables that contributed the most to the separation between plant types, whereas the horizontal axis explained $12 \%$ of the variation between plant types, with foliar weight $(r=0.526, P<0.001)$ and plant growth $(r=0.519$, $P<0.001$ ) as the variables separating plant types (Figure 1).

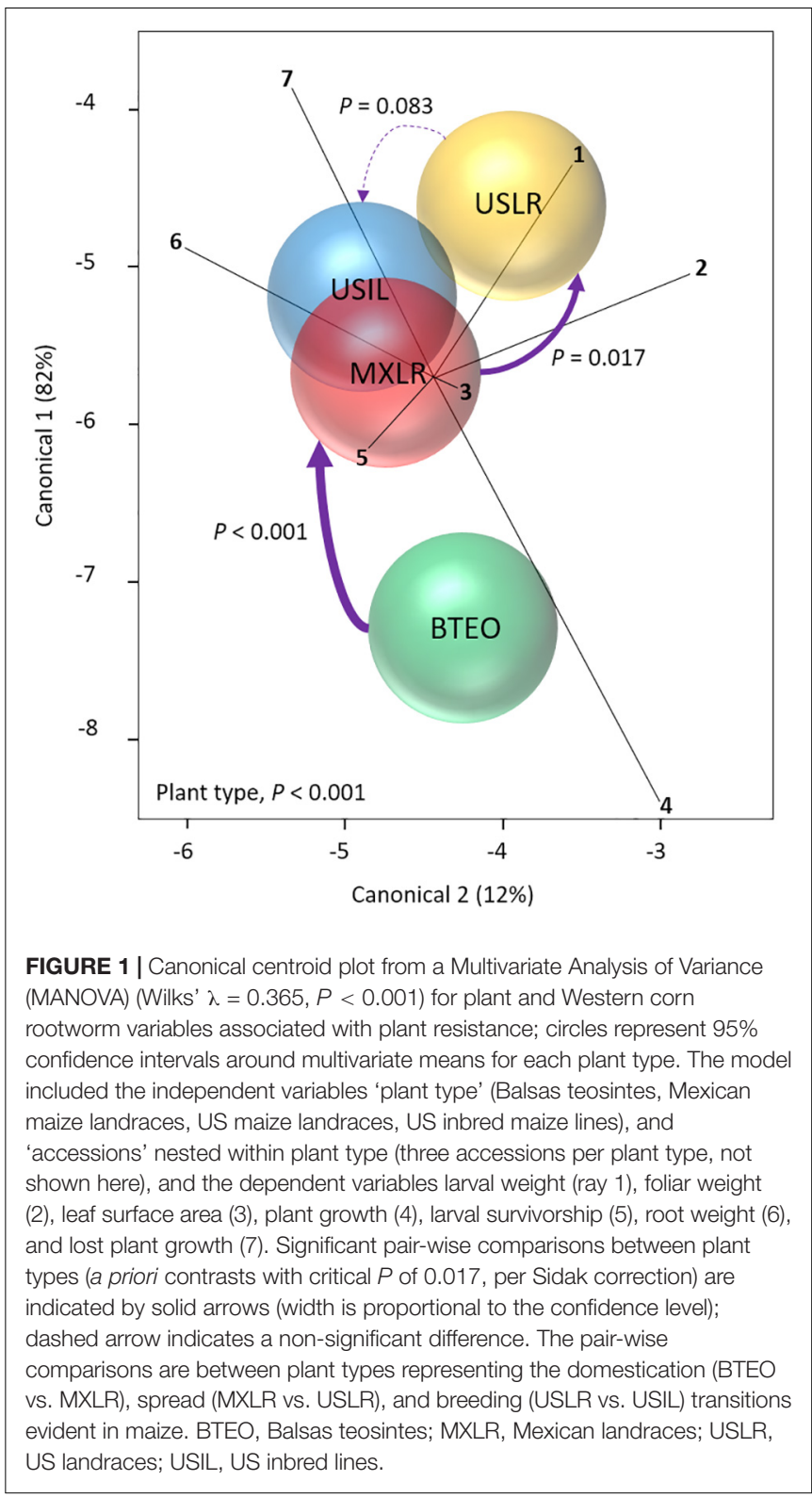

Analysis of variance on each dependent variable revealed significant plant type effects on foliar ratio, root ratio, and larval weight, growth rate, and lost growth $(P \leq 0.026)$, but no effect on leaf surface area and larval survivorship (Table 1). A priori contrasts between plant types were applied to each significant dependent variable to assess domestication, spread, and breeding effects. These contrasts revealed significant differences between Balsas teosintes and Mexican landraces in foliar and root ratios $(P \leq 0.005)$; between Mexican landraces and US landraces in foliar ratio $(P=0.001)$, and; between US landraces and US inbred lines in foliar ratio, and larval weight $(P \leq 0.008)$ (Figure 2$)$.

The distributions of larval instar frequencies varied among plant types ( $G=40.43,6$ d.f., $P<0.001$ ) (Figure 3A). Pairwise comparisons of frequency distributions showed significant differences between Balsas teosintes and Mexican landraces 
TABLE 1 | Analysis of variance (ANOVA) statistics for the independent variables 'plant type' (Balsas teosintes, Mexican maize landraces, US maize landraces, and US inbred maize lines) and seven plant and Western corn rootworm dependent variables associated with plant resistance.

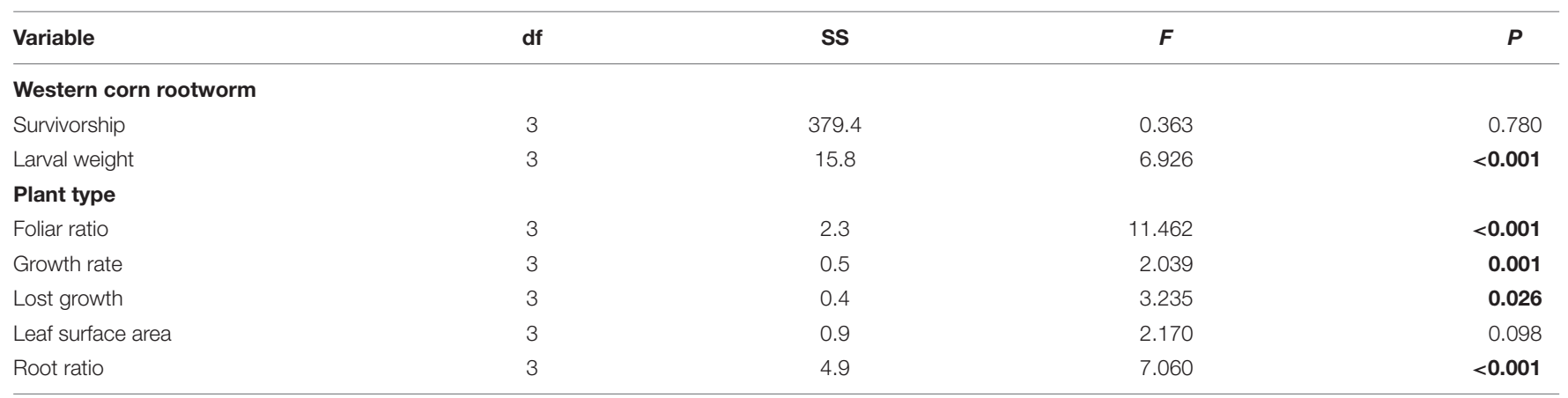

$P$-values for variables significantly affected by plant type are shown in bold $(P \leq 0.05)$.
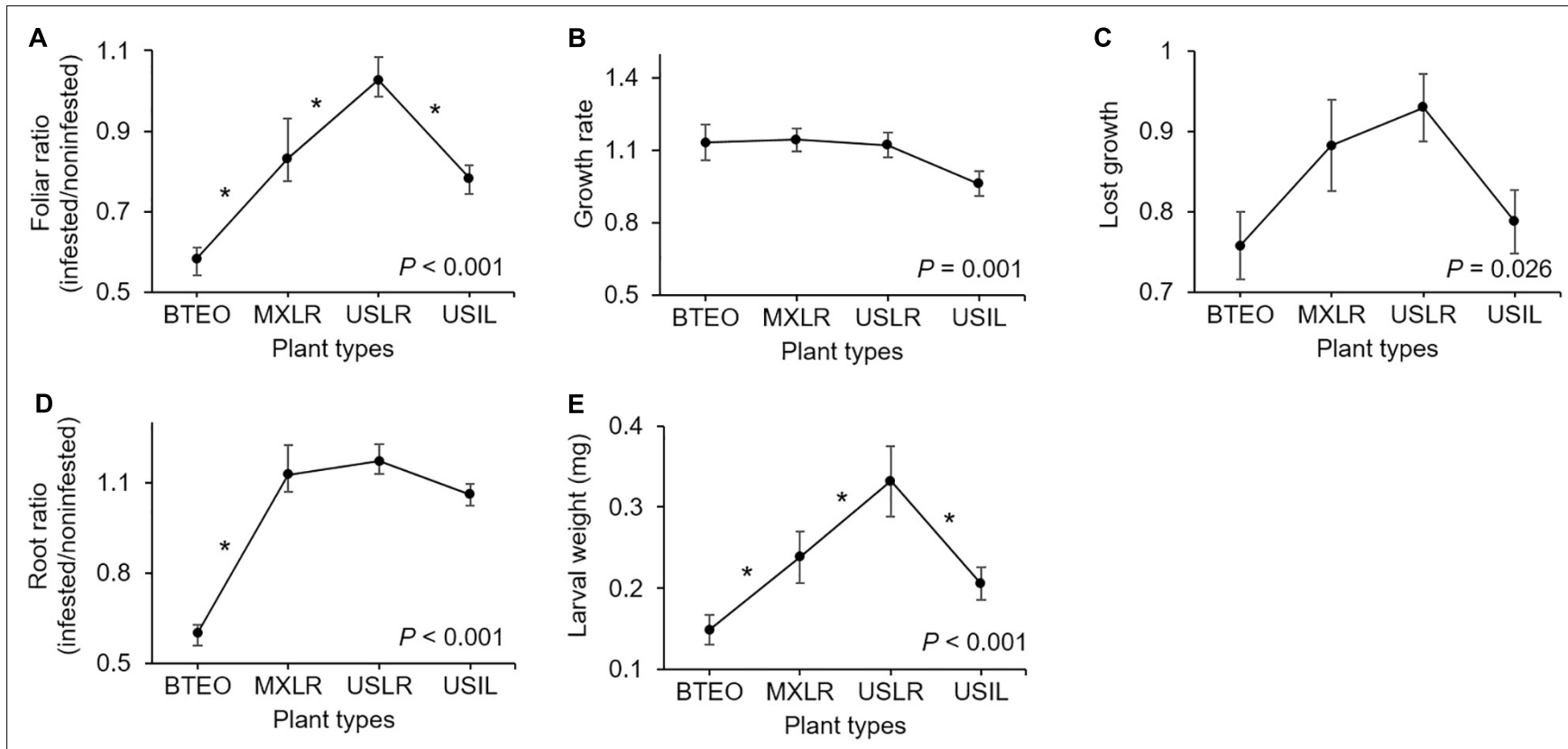

FIGURE 2 | Paired comparisons between per-plant type means ( \pm SE) of plant and Western corn rootworm (WCR) variables associated with plant resistance. Plant types are ordered left to right from most ancestral to most derived: Balsas teosintes (BTEO), Mexican maize landraces (MXLR), US maize landraces (USLR), and US maize inbred lines (USIL). Asterisks indicate significant difference (a priori contrasts with critical $P \leq 0.017$, per Bonferroni correction) between means of contiguous plant types representing the domestication (BTEO vs. MXLR), spread (MXLR vs. USLR), and breeding (USLR vs. USIL) transitions in maize; univariate analysis of variance (ANOVA) $P$ statistics are inset in each plot (see Table 1 for complete statistics). (A) Foliar ratio (= above-ground weights after 10 days, WCR-infested plants/non-infested plants); (B) Growth rate (=ratio between WCR infested seedling stem diameter at days 0 and 10 of the assay); (C) Lost growth (=stem diameter ratio after 10 days of WCR-infested plants/non-infested plants); (D) Root ratio (=belowground weights after 10 days of WCR-infested plants/non-infested plants).

(E) Larval weight (=weights of WCR larvae after 10 days).

$(G=17.82,2$ d.f., $P<0.001)$, US landraces and US inbred lines $(\mathrm{G}=17.32,2$ d.f., $P<0.001)$, but not between Mexican landraces and US landraces $(G=2.34,2$ d.f., $P=0.309)$, i.e., significant domestication and breeding effects, but not spread effects (Figure 3A). The development speed of WCR larvae did not differ significantly among plant types $\left(F_{3,8}=2.33\right.$, $P=0.150)$ (Figure 3B).

Overall, these results suggested that Zea resistance to WCR decreased with domestication and spread, and was partially recovered by breeding. Balsas teosintes appeared as the most resistant plant type, US landraces as the least resistant, and Mexican landraces and US inbred lines as intermediately resistant.

\section{Plant Tolerance}

MANOVA (overall Wilk's $\lambda=0.142, P<0.001$ ) revealed significant effects of herbivory $\left(F_{4,156}=16.555, P<0.001\right)$, plant type $(\lambda=0.622, P<0.001)$, and herbivory $\times$ plant type interaction $(\lambda=0.869, P=0.025)$ on seedling tolerance levels to WCR feeding (Figure 4). A priori contrasts within plant types revealed significant differences between WCR-infested and -noninfested Balsas teosinte $\left(F_{4,164}=9.922, P<0.001\right)$, Mexican 

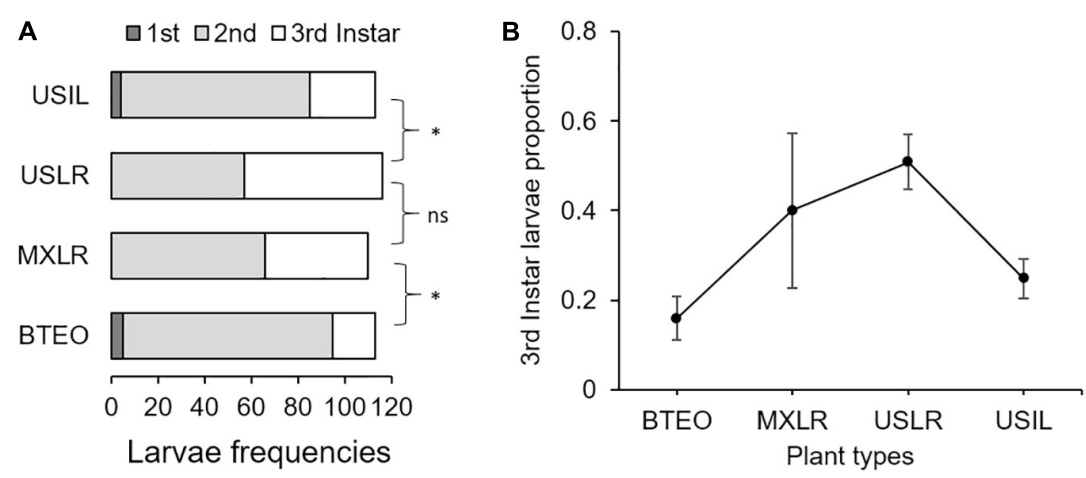

FIGURE 3 | (A) Frequency distributions of 1st-, 2nd-, and 3rd-instar larvae, and (B) development speed (=proportion of larvae reaching 3rd-instar) of larvae of Western corn rootworm in trials concluding 10 days after neonates were allowed to feed on one of four plant types. Plant types were Balsas teosintes (BTEO), Mexican maize landraces (MXLR), US maize landraces (USLR), and US inbred maize lines (USIL), and are ordered from most ancestral to most derived. A priori, pair-wise comparisons between frequency distributions representing the domestication (BTEO vS. MXLR) and breeding (USLR vs. USIL) transitions were significant $\left({ }^{*} \mathrm{G} \geq 17.25, P<0.001\right)$, while the comparison representing the spread transition (MXLR vs. USLR) was not significant $(G=2.34, P=0.309)$; the critical $P$-value for these comparisons was set at $P \leq 0.017$, per Sidak's correction. Univariate analysis of variance (ANOVA) indicated that development speed did not vary across plant types $\left(F_{3,8}=2.33, P=0.150\right)$.

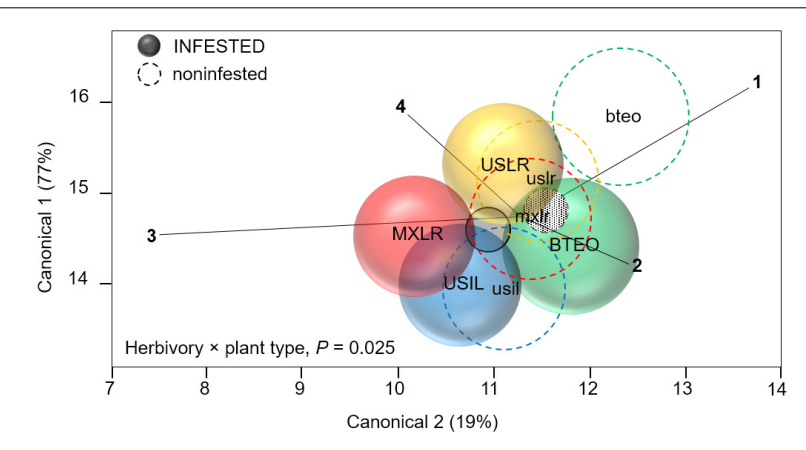

FIGURE 4 | Canonical centroid plot for multivariate analysis of variance (MANOVA) on plant variables associated with plant tolerance to feeding by Western corn rootworm; circles represent 95\% confidence intervals around multivariate means for each plant type. The model includes the independent variables 'plant type' (Balsas teosintes, Mexican maize landraces, US maize landraces, US inbred maize lines), 'accessions' nested within plant type (three accessions per plant type, not shown here), herbivory (Western corn rootworm presence or absence) and the interaction term 'herbivory $\times$ plant type.' The dependent variables were foliar weight (ray 1), leaf surface area (2), final stem diameter (3), and root weight (4). The overall model (Wilks' $\lambda=0.142, P<0.001)$ and main effects were significant: plant type $(\lambda=0.622$, $P<0.001)$, herbivory $\left(F_{4,164}=16.555 P<0.001\right)$, and herbivory $\times$ plant type $(\lambda=0.869, P=0.025)$. Pair-wise comparisons between Western corn rootworm-infested and -non-infested plants within plant types (depicted by continuous circles/upper-text and dashed circles/lower-case text) were significant for all plant types, except for US landraces (red circles): Balsas teosintes, $F_{4,164}=9.922, P<0.001$; Mexican landraces, $F_{4,164}=4.115$, $P=0.003$; US landraces. $F_{4,164}=2.253, P=0.065$; US inbred lines,

$F_{4,164}=4.684, P=0.001$. Smallest circles (filled) near plot center represent overall Western corn rootworm-infested (solid line and filling) and -non-infested (dashed line, patterned filling) plants. BTEO, bteo, Balsas teosintes infested or non-infested, respectively, by Western corn rootworm; MXLR, mxIr, Mexican landraces; USLR, usIr, US landraces; USIL, usil, US inbred lines.

landrace maize $\left(F_{4}, 164=4.115, P=0.003\right)$, and US inbred maize $\left(F_{4}, 164=4.684, P=0.001\right)$, but not within US landrace maize $\left(F_{4}, 164=2.253, P=0.065\right)$ (Figure 4$)$, suggesting that only US landraces displayed broad tolerance to WCR feeding. Correlation analysis of canonical scores showed that the vertical axis of the centroid plot explained $77 \%$ of the variation, with final stem diameter $(r=0.67, P<0.001)$, foliar weight $(r=0.91, P<0.001)$, and root weight $(r=0.90, P<0.001)$ as the variables that most contributed to the separation between infested and non-infested plant types. The same analysis showed that the horizontal axis explained $19 \%$ of the variation between infested and non-infested plant types, with leaf surface area as the main explanatory variable $(r=0.53, P<0.001)$ (Figure 4).

Within each plant type, tissue losses, assessed as mean ratios (= WCR-infested seedlings/non-infested seedlings) of foliar weight, leaf surface area, final stem diameter, and root weight, were found to be undercompensated (i.e., ratio $<1.0$, $P<0.001)$ in both Balsas teosintes and US inbred lines, with the exception of root tissue, which was compensated in US inbred lines (i.e., ratio $>1.0, P=0.780$ ) (Figure 5). Mexican landraces compensated foliar, final stem diameter and root tissue losses (i.e., ratio did not differ from 1.0, $P \geq 0.019)$, and undercompensated leaf surface area losses $(\mathrm{P}<0.001)$. Finally, US landraces compensated all tissue losses, foliar, leaf surface area, final stem diameter, and root tissue $(P \geq 0.020)$. These results suggested that US landraces displayed tolerance to WCR as they consistently compensated tissue losses, Mexican landraces and US inbreds displayed partial tolerance, and Balsas teosintes did not display tolerance (Figure 5).

Herbivory $\times$ plant type interaction effects are shown in Figure 6. Significant differences between infested and noninfested seedlings were found for foliar $\left(F_{3,167}=3.126, P=0.027\right)$ and root $\left(F_{3,167}=4.039, P=0.008\right)$ weights, but not for final stem diameter $\left(F_{3,167}=0.8140, P=0.487\right)$ nor leaf surface area $\left(F_{3,167}=0.471, P=0.702\right)$. A priori contrast comparisons between infested and non-infested seedlings ( $P \leq 0.012$; Sidak corrected) revealed significant foliar tissue losses (i.e., undercompensation) in Balsas teosintes $\left(F_{1,167}=27.536, P<0.001\right)$ and Mexican 


\begin{tabular}{|r|c|c|c|c|}
\hline \multicolumn{5}{c}{ Tissue lost or gained } \\
\hline \multirow{5}{*}{ Foliar } & BTEO & MXLR & USLR & USIL \\
\cline { 2 - 5 } & $0.83 \pm 0.14$ & $0.92 \pm 0.03$ & $1.00 \pm 0.02$ & $0.92 \pm 0.01$ \\
& $\downarrow$ & $\leftrightarrow$ & $\leftrightarrow$ & $\downarrow$ \\
& $<0.001$ & 0.019 & 0.957 & $<0.001$ \\
\cline { 2 - 6 } Leaf surface area & $0.80 \pm 0.03$ & $0.80 \pm 0.04$ & $0.90 \pm 0.04$ & $0.84 \pm 0.04$ \\
& $\downarrow$ & $\downarrow$ & $\leftrightarrow$ & $\downarrow$ \\
& $<0.001$ & $<0.001$ & 0.020 & $<0.001$ \\
\cline { 2 - 6 } Final stem diameter & $0.76 \pm 0.04$ & $0.88 \pm 0.06$ & $0.93 \pm 0.04$ & $0.79 \pm 0.04$ \\
& $\downarrow$ & $\leftrightarrow$ & $\leftrightarrow$ & $\downarrow$ \\
& $<0.001$ & 0.051 & 0.110 & $<0.001$ \\
\cline { 2 - 6 } Root & $0.82 \pm 0.03$ & $1.00 \pm 0.04$ & $1.04 \pm 0.02$ & $1.01 \pm 0.02$ \\
& $\downarrow$ & $\leftrightarrow$ & $\leftrightarrow$ & $\leftrightarrow$ \\
& $<0.001$ & 0.991 & 0.047 & 0.780 \\
\hline
\end{tabular}

FIGURE 5 | Effects of herbivory by Western corn rootworm on plant tolerance variables in four plant types, ordered from most ancestral to most derived: Balsas teosintes (BTEO), Mexican maize landraces (MXLR), US maize landraces (USLR), and US inbred maize lines (USIL). The plant tolerance variables are mean ratios (= Western corn rootworm-infested plants/non-infested plants) of final stem diameters, foliar weights, leaf surface areas, and root weights. One-sample $t$-tests were used to compare mean ratios for each plant type against expected ratio of 1.0 , which indicates tissue compensation (i.e., no tissue lost or gained in Western corn rootworm-infested plants relative to non-infested plants); the mean ratio $( \pm \mathrm{SE})$ and $P$-value are shown within each cell. Within each cell, double-pointed, horizontal green arrows indicate compensation (mean ratio does not differ from 1.0), and downward, red arrows indicate undercompensation (mean ratio < 1.0). Critical $P$ for each $t$-test was set at $P \leq 0.012$, per Sidak's correction.

landraces $\left(F_{1,167}=7.543, P=0.007\right)$, while US landraces $\left(F_{1,167}=0.890, P=0.346\right)$ and US inbred lines $\left(F_{1,167}=4.127\right.$, $P=0.041$ ) did not lose nor gain tissue (i.e., compensation) (Figure 6A). A priori contrast comparisons for root weights revealed that Balsas teosintes lost tissue (i.e., undercompensation) $\left(F_{1,167}=13.576, P<0.001\right)$, whereas Mexican landraces $\left(F_{1,167}=0.005, P=0.942\right)$, US landraces $\left(F_{1,167}=0.424\right.$, $P=0.515)$, and US inbred lines $\left(F_{1,167}=0.158, P=0.691\right) \mathrm{did}$ not lose nor gain tissue (i.e., compensation) (Figure 6B).
Overall, these results suggested that Zea tolerance to WCR was gained with domestication and reinforced by spread. However, it also suggested that breeding weakened tolerance to a point comparable to that evident in Mexican landraces. The tolerance levels, ordered from most to least tolerant plant type appeared to be US landraces, Mexican landraces, and US inbreds, while Balsas teosintes appeared to be intolerant.

\section{Plant Resistance-Plant Tolerance Trade-Off}

Correlation analysis showed a significant negative correlation between per-plant accession larval weights and differences in foliar weights between WCR-infested and non-infested seedlings ( $r=-0.646, P=0.023$ ) (Figure 7). Consistent with the Plant resistance and Plant tolerance results, the analysis suggested that Balsas teosintes was the most resistant plant type, US landraces was the least resistant, and Mexican landraces and US Inbred lines were intermediately resistant. Conversely, it suggested that US landraces was the most tolerant plant type, Balsas teosintes was the least tolerant, and Mexican landraces and US Inbred lines were intermediately tolerant. Overall, these results suggested that resistance declines with increasing tolerance in Zea.

\section{DISCUSSION}

This study addressed whether maize defense, in the forms of resistance and tolerance to WCR herbivory, was mediated by domestication, spread, and breeding processes that spanned divergent environments and thousands of maize and WCR generations. We expected to find that maize resistance against WCR was weakened with domestication, spread, and breeding, and that tolerance to WCR increased as resistance decreased. On one hand, our results showed that maize resistance indeed decreased from Balsas teosintes to US landraces, i.e., with maize domestication and spread, though, surprisingly, the trend seems to have reversed with breeding: US inbred lines showed more resistance to WCR than their US landrace ancestors,

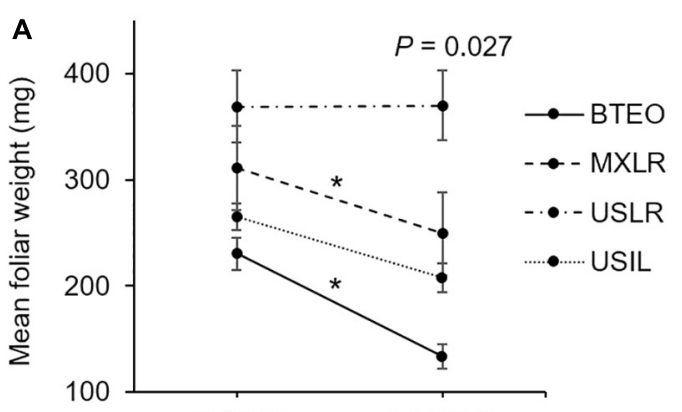

(-) WCR

(+) WCR

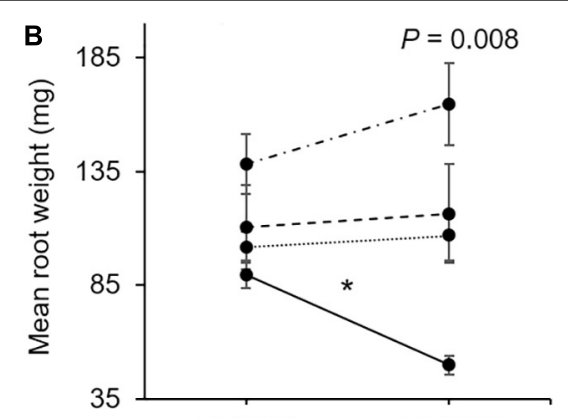

(-) WCR (+) WCR

FIGURE 6 | (A) Above- and (B) belowground tissue losses in four plant types, Balsas teosintes (BTEO), Mexican maize landraces (MXLR), US maize landraces (USLR), and US inbred maize lines (USIL), exposed to root herbivory by Western corn rootworm (WCR) larvae. Inset in each plot are the univariate analysis of variance (ANOVA) statistics for the herbivory $(+W C R,-W C R) \times$ plant type effect in foliar weight $\left(F_{3,167}=3.126, P=0.027\right)$ and root weight $\left(F_{3,167}=4.039\right.$, $P=0.008)$. Comparisons between plant types exposed (+WCR) and unexposed (-WCR) to Western corn rootworm larvae were made via a priori contrasts, with a critical $P$-value for each paired comparison set at $P \leq 0.012$, per Sidak's correction. Significant herbivory effects are indicated by an asterisk $\left({ }^{*}\right)$. 


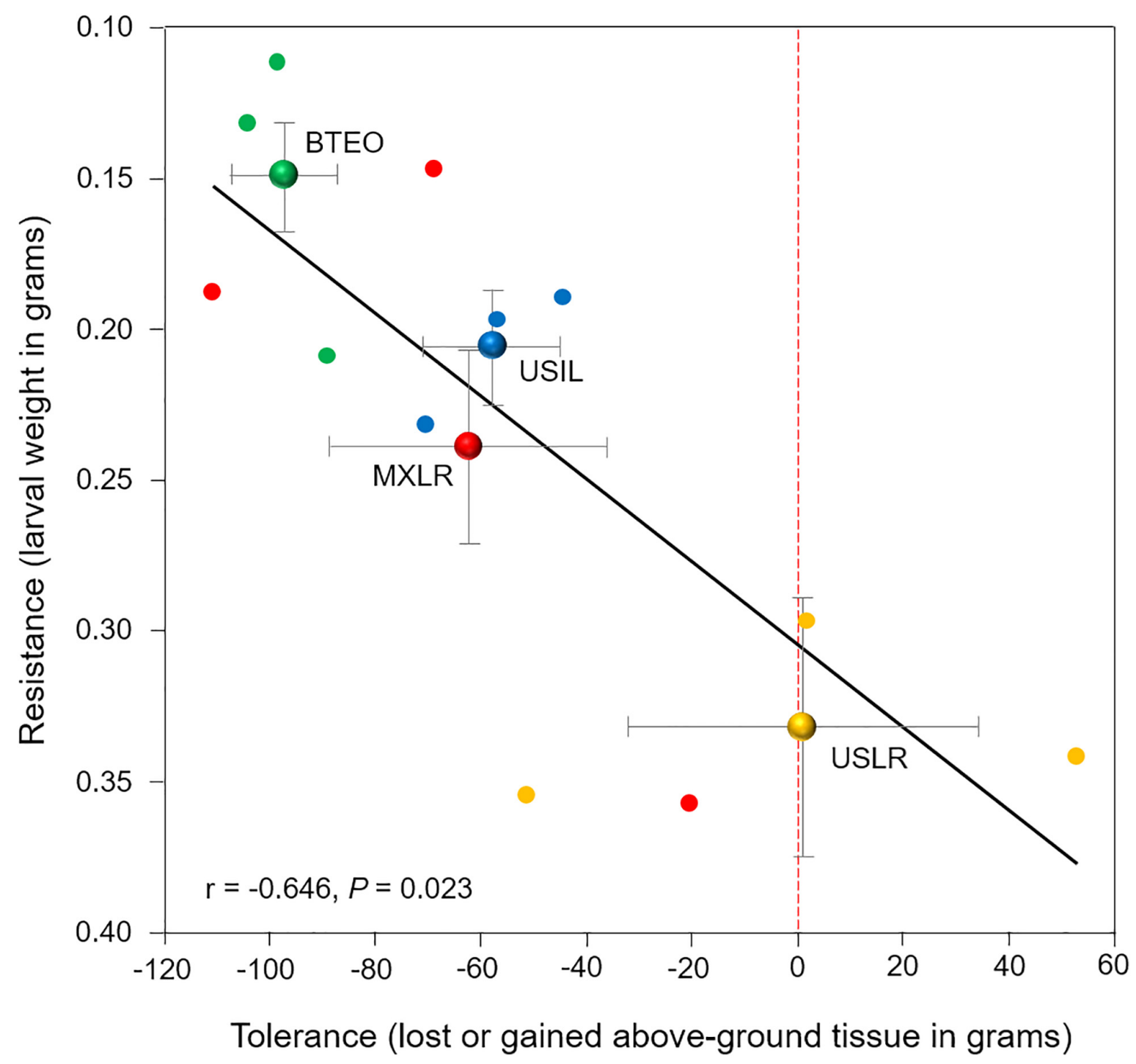

FIGURE 7 | Relationship between resistance (expressed as larval weight) and tolerance (expressed as plant tissue loss or gain) to root herbivory by Western corn rootworm larvae in 12 plant accessions (small circles), with three accessions corresponding to each of four plant types (large circles with bi-directional standard error bars). (Note that $Y$-axis values increase from top to bottom). Plant types are Balsas teosintes (BTEO), Mexican maize landraces (MXLR), US maize landraces (USLR), and US inbred maize lines (USIL). The weight of Western rootworm larvae (g) after 10 days of feeding on each accession was used as a proxy for resistance, while the loss or gain of above-ground tissue (g) of each accession after 10 days of exposure to root herbivory by rootworm larvae was used as a proxy for tolerance. Inset is Pearson's correlation $r$ statistic corresponding to the 12 plant accessions. The red, dotted vertical line on $x$-axis indicates tissue compensation (i.e., no tissue lost nor gained); means to the left of the dotted line are suggestive of undercompensation for tissue loss, and means to the right are suggestive of overcompensation for tissue loss.

so were intermediately resistant rather than least resistant. On the other hand, tolerance indeed increased as resistance decreased, as expected.

\section{Maize Resistance Decreased With Domestication and Spread, but Increased With Breeding}

MANOVA revealed a strong multivariate effect of plant type on resistance variables, and a priori comparisons showed significant differences between Balsas teosintes and Mexican landraces, as well as between Mexican landraces and US landraces, but not between US landraces and US inbreds. Similarly, ANOVAs showed both domestication and spread effects, especially on WCR larval performance (i.e., weight), which was enhanced on Mexican landraces compared to Balsas teosintes, as well as on US landraces compared to Mexican landraces. However, WCR larval performance declined on US inbreds compared to US landraces, in partial contrast to our MANOVA results. Moreover, an a posteriori contrast comparison between Balsas teosintes and US inbred lines showed no significant differences in larval weight and lost plant growth 
$\left(F_{1,167}=4.033, P=0.046\right.$; data not shown; Sidak-corrected critical $P \leq 0.012$ ). This result may indicate significant allocation of resources to defense against WCR in US inbred lines, as would be expected to support enhanced resistance. Overall, these results suggested that domestication and spread affected resistance, as we anticipated and in agreement with other studies (Bazzaz et al., 1987; Rosenthal and Dirzo, 1997; RodriguezSaona et al., 2011), but resistance was partly recovered with breeding, contrary to expected. The optimal plant defense hypothesis predicts that there is a cost of defense, particularly that metabolic resources cannot be simultaneously used to defend, grow, and reproduce, so that plant fitness increases when herbivory decreases or is absent (Stamp, 2003). This prediction did not seem to apply to US inbred lines, which appeared to compensate root tissue (see below) while decreasing WCR larval weight.

Our results suggested two, non-exclusive defense strategies related to plant defense biochemistry. First, the nutritional value of Zea host plants may have increased from Balsas teosinte to US landrace maize, but decreased in US inbred maize. Changes in nutrient composition may cause differences in larval weight and development, while maintaining survivorship (Meihls et al., 2018). WCR uses a blend of sugars and fatty acids, but not amino acids, as phagostimulants to accept and feed on maize (Bernklau and Bjostad, 2008). Sucrose, although of nonnutritional value to most insects, is known to be an important phagostimulant, including for larvae of Coleoptera, and may be more relevant for host plant acceptance or rejection than any amino acid considered important for insect development (Chapman, 2003). However, there are no direct studies, to our knowledge, comparing root nutritional value among Zea plants, though, Zea has experienced selection in $2-4 \%$ of its genome, resulting in numerous biochemical differences among teosintes, landraces, and inbred lines (Dorweiler et al., 1993; Wright et al., 2005; Flint-Garcia et al., 2009; de Lange et al., 2014). Secondly, maize landraces may be down-regulating some secondary metabolites, while maize inbreds may be upregulating them to levels similar to those in Balsas teosinte (Qu et al., 2016; Fontes-Puebla et al., unpublished). The composition of secondary metabolites has been altered by domestication in various crops, affecting their interactions with specialist and generalist insects (Da Costa and Jones, 1971; Howe et al., 1976; Gols et al., 2008; Chacon-Fuentes et al., 2015). Typically, generalist herbivores perform better on domesticated plants compared to their wild relatives due to a reduction in secondary metabolites (Rodriguez-Saona et al., 2011; Bellota et al., 2013; Szczepaniec et al., 2013; Turcotte et al., 2014; Bernal et al., 2015; Chen et al., 2015b; Maag et al., 2015). WCR shifted to maize when the crop reached northern Mexico (Lombaert et al., 2017), and encountering maize landraces with weaker defenses than its original, wild host may have been advantageous for the quasi-specialist WCR (Branson and Ortman, 1967, 1970; Hahn and Maron, 2016). Maize breeding, conversely, may have partly reversed the decreasing trend of secondary metabolite levels, without a concurrent effect on maize productivity. Maize per-plant productivity (but not per-area yields) seems to have reached a maximum several decades ago, so that any productivity costs of chemical defense may be negligible, while breeding efforts may have inadvertently selected for WCR resistance, as evident for other maize pests (Duvick, 2005). Regardless of the relative importance of either defense strategy, the differences in WCR and seedling responses among plant types in our study were consistent with hypotheses of resistance reductions with domestication and spread (Rosenthal and Dirzo, 1997; Whitehead et al., 2017; Zust and Agrawal, 2017). However, breeding seemingly increased resistance (measured as decreased WCR performance) in US inbred lines, with no apparent cost to productivity. Further below, we discuss conditions under which resistance against WCR may have increased in US inbred maize concurrently with productivity, i.e., yield gains, particularly in the context of intensive maize agriculture reliant on modern technologies, such as synthetic fertilizers and pesticides, among others.

\section{Maize Tolerance Increased With Domestication and Spread, but Decreased With Breeding}

MANOVA revealed strong multivariate effects of plant type on tolerance variables, and contrast comparisons revealed increasingly smaller (but significant) differences between WCRinfested and control seedlings (as indicated by $F$ and $P$-values) in Balsas teosintes, Mexican landraces, and US inbreds, while a significant difference was not found in US landraces. In this regard, US landraces showed the smallest partial $\eta^{2}$ effect size of WCR infestation on seedling growth $\left(\eta_{\mathrm{p}}^{2}=0.055\right)$, while effect sizes were 3.6- $\left(\eta_{\mathrm{p}}^{2}=0.200\right), 2.4-\left(\eta_{\mathrm{p}}^{2}=0.134\right)$, and 1.9-fold greater $\left(\eta_{\mathrm{p}}^{2}=0.107\right)$ in Balsas teosintes, Mexican landraces, and US inbreds, respectively (data not shown) (Richardson, 2011). Similarly, our univariate analyses showed that US landraces consistently compensated for tissue losses, while Mexican landraces and US inbreds inconsistently compensated for tissue losses, and Balsas teosintes consistently undercompensated for tissue losses. Finally, measured as total above- or belowground tissue losses, Balsas teosintes lost both above- and belowground tissue with WCR feeding, Mexican landraces and US inbreds lost aboveground tissue, and US landraces compensated for above- and belowground tissue losses. Taken together, these results suggested that tolerance was strongest in US landraces, weakest in Balsas teosintes, and intermediate in Mexican landraces and US inbreds.

Domestication and subsequent farming could favor tolerance evolution when abiotic factors (e.g., soil nutrients, light availability) mediate the selection of plant defenses against herbivores (Hahn and Maron, 2016). Annual crops, grown as they typically are, in resource rich environments are predicted to maximize fitness by allocating resources toward growth and reproduction, and trading-off constitutive resistance to herbivory (Herms and Mattson, 1992; Rosenthal and Dirzo, 1997; Simms, 2000). Additionally, biotic factors may impose selective pressures on domesticated plants. For example, in Hahn and Maron's (2016) framework for intraspecific variation of plant defenses, two factors mediate defense evolution to tolerance or 
resistance: Low physiological stress (selecting for fast growing plants) and herbivory pressure (selecting for induced resistance). Importantly, WCR may indirectly select for tolerance as it is able to manipulate its host's quality by inducing it to allocate primary metabolites (e.g., carbon, phosphorus, among others) to roots (Robert et al., 2012a). Such allocation may increase root compensation and, therefore, tolerance to root herbivory, and plants able to compensate for root herbivory may be favored by selection (cf. Figures 5,6 ). In parallel, this may explain the increased resistance and weakened tolerance in US inbred lines compared to US landraces. US inbred lines have been bred in contexts of low physiological stress and high WCR herbivory, especially since the 1940s, compared to the contexts in which their ancestral landraces were grown and selected (see below).

\section{Maize Resistance and Tolerance Trade-Off}

Overall, our results showed a negative correlation between resistance and tolerance, consistent with optimal defense hypotheses and our expectation (Herms and Mattson, 1992; Blossey and Notzold, 1995; Zou et al., 2007; Hahn and Maron, 2016). However, we expected that this correlation would be consistent also with the evolutionary transitions between Balsas teosintes and US inbred lines. Usually, trade-offs are observed when fitness is compromised due to competing resource demands, e.g., resistance and fast growth, and natural selection may benefit one or the other depending on their direct or ecological costs (Strauss et al., 2002; Agrawal et al., 2010). Artificial selection, however, may favor a trade-off between a desired trait and a less-desired trait, e.g., selection for productivity and weakened resistance, as our results suggested for Mexican landraces. In contrast, US landraces may have been selected for herbivory tolerance under increased WCR pressure and resource availability (Agrawal et al., 2010; Kutka, 2011). Furthermore, plant resistance may de-escalate when a plant's herbivore fauna is dominated by mono- or oligophagous insects, such as WCR (Agrawal and Fishbein, 2008; Agrawal et al., 2010). WCR became a pest after maize agriculture spread to North America, and may have been an important selection force shaping the defenses of modern maize in the US. The extended, millennia-long association between maize and WCR - punctuated with severe WCR bottlenecks when maize agriculture became dominant in (current) southwestern (ca. $500 \mathrm{YBP}$ ) and northern (ca. $180 \mathrm{YBP}$ ) USA states - may have led to an evolutionary compromise, with maize gaining tolerance and WCR becoming a specialist (Robert et al., 2012a, 2017; Lombaert et al., 2017).

\section{Disarmed by Agricultural Intensification: Maize Traded Western Corn Rootworm Tolerance for Token Resistance}

Our results addressing the effects of maize domestication and spread on defense strategy evolution were consistent with theoretical predictions concerning resistance and tolerance evolution in the contexts of plant productivity-resistance trade-offs and plant resistance-tolerance trade-offs, respectively (Agrawal et al., 2010; Pearse et al., 2017; Zust and Agrawal, 2017).
However, the effects of breeding were inconsistent with those predictions in that US inbred lines were less tolerant and more resistant to WCR than their ancestral US landraces. We believe that this reversal is a result of agricultural intensification of maize production, particularly the systematic breeding of maize varieties for maximum yield under the umbrella of commercial, synthetic fertilizers, irrigation, and pesticides (Bernal and Medina, 2018). Under such intensification, pesticides provided relief from WCR injury without a metabolic cost to the crop, and fertilizers coupled with irrigation enhanced plant nutrient levels to support on one hand the productivity increases gained with systematic breeding, and on the other to offset any productivity losses due to WCR and other pests. This intensification period began in the late 1940s with the widespread availability of hybrid maize varieties, chemical fertilizers, and pesticides, and in the context of increasing pressure by WCR, which up to then had not been a significant pest (Perkins, 1982; Palladino and Fitzgerald, 1996; Duvick, 2005; Gray et al., 2009; Kutka, 2011; Smith, 2011; Lombaert et al., 2017). In contrast, the period prior to intensification was characterized by natural and farmer (artificial) selection of maize landraces for broad resistance to environmental stresses, the absence of pesticides and commercial fertilizers, and minimal WCR pressure; this period ended with the deployment of commercial hybrid varieties, and decline of landraces, beginning in the 1930s (Duvick, 2005; Kutka, 2011; Smith, 2011; Bernal and Medina, 2018).

Overall, our results were consistent not only with predictions concerning plant defense evolution in the contexts of plant productivity-resistance trade-offs and plant resistance-tolerance trade-offs, as noted above, but also with predictions concerning defense strategy evolution in the context of variable resource availability and environmental stresses, particularly physiological stress (under low resource availability) and herbivory pressure (Herms and Mattson, 1992; Blossey and Notzold, 1995; Zou et al., 2007; Hahn and Maron, 2016) (Figure 8). We believe that shifts in resource availability, WCR pressure, and farmer selection of maize landraces to systematic breeding of maize inbred lines between the pre-intensification and intensification periods of maize production mediated the evolution of WCR defenses in US inbred maize lines (Duvick, 2005; Gray et al., 2009; Ivezić et al., 2009; Kutka, 2011; Smith, 2011; Lombaert et al., 2017; Mesa et al., 2017). For example, while the slight gain in WCR resistance evident in US inbred lines was not anticipated per expectations under a productivity-resistance trade-off, it was an anticipated result of directed systematic breeding for WCR resistance (and inadvertent selection under WCR pressure), and was associated with a loss of tolerance, as anticipated under a resistancetolerance trade-off (Duvick, 2005; Agrawal, 2006; Agrawal and Fishbein, 2008; Gray et al., 2009; Ivezić et al., 2009; Agrawal et al., 2010). In Figure 8A, we show how resource availability may have increased (indicated by the arrow's increasingly dark coloration) with maize domestication and spread, as maize by that time an important food crop - was subjected to site selection and cultural practices aimed at enhancing its productivity. Concomitantly, physiological stress gradually may have lost importance as a driver of herbivore defense evolution as resource availability increased (see horizontal arrow at top 


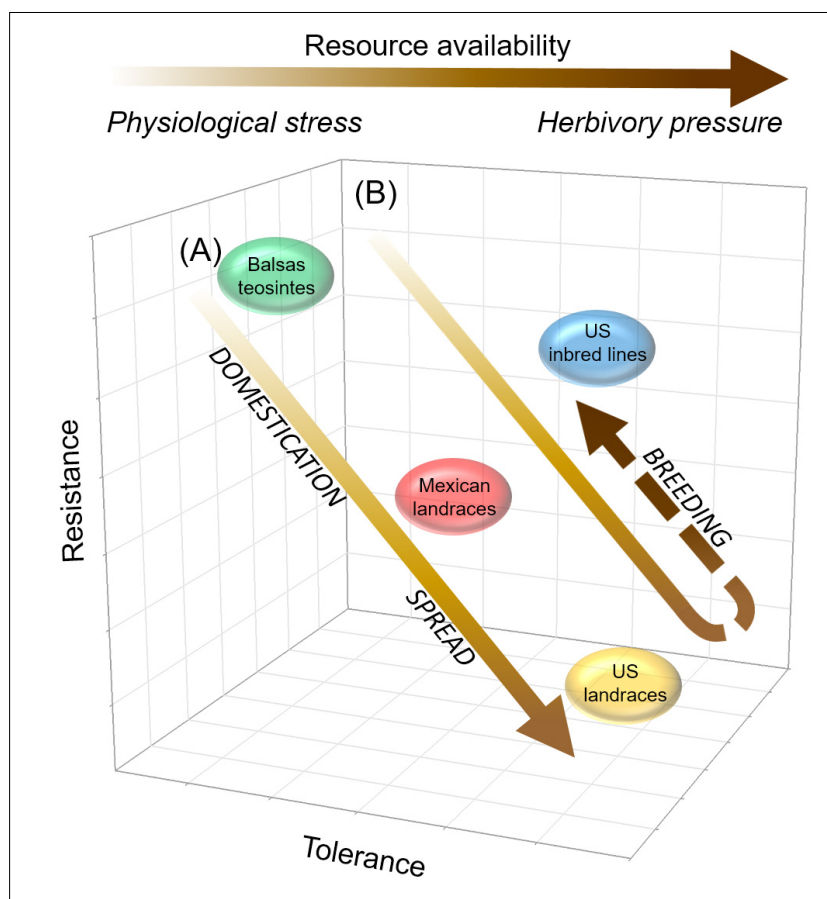

FIGURE 8 | Hypothesized relationship between plant tolerance and resistance in maize, as mediated by agricultural intensification, resource availability, and environmental stress. In this study's context, agricultural intensification refers to widespread cultivation of high-yielding maize cultivars developed through systematic breeding, under the umbrella of chemical inputs, particularly commercial insecticides and synthetic fertilizers, and under increasing WCR pressure (see Text for additional details). The high-yielding cultivars are hybrids generated from inbred lines, which require chemical fertilizers (and adequate moisture) and pesticides to reach maximum productivity. The prior, pre-intensification period is characterized by widespread cultivation of landrace maize, natural and farmer (artificial) selection of landraces for broad resistance to environmental stresses, absence of fertilizers and pesticides, and minimal WCR pressure. (A) Prior to agricultural intensification, resistance to WCR gradually decreases while tolerance increases with maize domestication and spread, as resource availability increases, and as physiological stress gradually loses relevance to defense strategy evolution. (B) The trend of WCR resistance loss with WCR tolerance gain is reversed with breeding under agricultural intensification, where resource availability is high, physiological stress is minimized with the advent of chemical fertilizers, and WCR pressure becomes relevant to defense strategy evolution, though its relevance is mediated by insecticide use. In arrows in both $(\mathbf{A}, \mathbf{B})$, and in horizontal arrow at top of figure, the lighter to darker gradient in coloration indicates an increasing gradient of resource availability; within this gradient, physiological stress and herbivory pressure are most relevant to defense strategy evolution at the low- and high-resource availability extremes, respectively.

of Figure 8, showing how resource availability is relevant to defense evolution at low resource availability, while herbivory pressure is relevant at high resource availability). In Figure 8B, we show how resource availability may have continued to increase and reached its highest level with the breeding transition, particularly with the advent of commercial fertilizers to support cultivation of high-yielding maize cultivars, i.e., intensification. At the same time, WCR emerged as an important pest of maize, and while it may have become a significant driver of herbivore defense evolution, its significance was mediated by the use of insecticides, which became widely available as maize agriculture was increasingly intensified. Altogether, we believe that our results illustrate how the evolution of defense strategies in maize, and perhaps other crops, is predicted by ecological-evolutionary hypotheses predicting defense strategy evolution in the contexts of plant resistance-productivity tradeoffs, plant tolerance-resistance trade-offs, and varying resource availability vis-à-vis plant physiological stress and herbivory pressure (Herms and Mattson, 1992; Blossey and Notzold, 1995; Zou et al., 2007; Hahn and Maron, 2016).

\section{CONCLUSION}

Put together, our results conformed to an unsurprising account in which maize defenses against Western corn rootworm were significantly impacted by processes spanning thousands of maize and WCR generations across divergent environments, namely domestication, spread to North America, and systematic breeding during the last $\sim 100$ years. Surprisingly, however, the end result of those processes were US inbred lines that were not the least resistant and most tolerant among the four maize types that were studied, as we expected. Instead, we found that levels of resistance and tolerance to WCR in US inbred lines were intermediate between those in Balsas teosinte, which we considered resistant, and US landraces, which we considered tolerant, and similar to those in Mexican landraces. This result is significant for at least two reasons. First, because it indicates that US inbred lines, i.e., the parents of commercial hybrid varieties, are neither tolerant nor resistant to WCR, which may explain in part the decades-long need in commercial maize production for extrinsic means of defense against WCR, such as insecticides or insecticidal transgenes. That result is significant also because it suggests that our study's main findings were predictable based on ecological-evolutionary theory, particularly in the context of increasing levels of resources for plant growth. An important implication of this is that such theory is applicable in agricultural contexts, so will be valuable for designing future pest management strategies broadly, and host plant resistance strategies particularly. Finally, future research should incorporate early US inbred lines, developed prior to agricultural intensification, as defined above, to address whether such intensification indeed mediated WCR resistance and tolerance, as posited here. Additionally, because our findings are based on organismal-level responses of maize seedlings and WCR, we believe that future studies should include reproductivestage plants, and seek mechanistic explanations for any responses, particularly by addressing any underlying herbivore defense biochemistry, from phytohormones to volatiles and secondary metabolites relevant to maize-WCR interactions.

\section{MATERIALS AND METHODS}

\section{Plants and Insects}

Four plant types belonging to the Zea genus were tested: Balsas teosinte, Mexican landraces, US landraces and US inbred lines (Table 2). These plant types were selected to represent the 
TABLE 2 | Plant types, accessions and number of bio-replicates per each (in parenthesis), and their geographic origins and reference numbers.

\begin{tabular}{|c|c|c|c|}
\hline Plant type & Accession & Origin & References $^{4}$ \\
\hline Balsas teosintes ${ }^{1}(25)$ & $\begin{array}{l}\text { El Cuyotomate (8) Talpitita (9) El } \\
\text { Rodeo (8) }\end{array}$ & $\begin{array}{l}\text { Jalisco state, Mexico: Ejutla, Ejutla } \\
\left(19^{\circ} 58^{\prime} \mathrm{N}, 104^{\circ} 04^{\prime} \mathrm{W}\right) \text { Talpitita, Villa } \\
\text { Purificación }\left(19^{\circ} 42^{\prime} \mathrm{N}, 104^{\circ} 48^{\prime} \mathrm{W}\right) \mathrm{El} \\
\text { Rodeo, Tolimán }\left(19^{\circ} 33^{\prime} \mathrm{N}, 104^{\circ} 03^{\prime} \mathrm{W}\right)\end{array}$ & --- \\
\hline Mexican landraces ${ }^{2}(21)$ & $\begin{array}{l}\text { Palomero Toluqueño (7) Chalqueño } \\
\text { (8) Cacahuacintle (6) }\end{array}$ & $\begin{array}{l}\text { Mexico state, Mexico: Toluca Valley, } \\
\text { Toluca San Mateo Atenco, San Mateo } \\
\text { Atenco Toluca Valley, Toluca }\end{array}$ & NSL 2824 PI 629215 NSL 2823 \\
\hline US landraces ${ }^{2}$ (23) & $\begin{array}{l}\text { Lancaster Sure Crop (7) Reid } \\
\text { Yellow Dent (8) Gourdseed (8) }\end{array}$ & $\begin{array}{l}\text { United States: Ohio Indiana Ennis, } \\
\text { Texas }\end{array}$ & PI 280061 PI 213698 PI 414179 \\
\hline US inbred lines (23) & $\mathrm{MO}^{2} 7^{2}(7) \mathrm{B}^{3} 3^{3}(8) \mathrm{W} 438^{3}(8)$ & United States: Missouri lowa Wisconsin & PI 558532 PI 550473 AMES 29447 \\
\hline
\end{tabular}

evolution of maize from its wild ancestor through the processes of domestication, spread, and breeding (Troyer, 1999; Matsuoka et al., 2002; Labate et al., 2003; Lombaert et al., 2017). Specifically, (i) Balsas teosinte is the immediate ancestor of maize, thus represented maize in its wild state, prior to domestication; (ii) Mexican landraces were included as descendants of Balsas teosinte, and served to assess the effects of domestication and the crop's early upland spread; (iii) US landraces were included as descendants of Mexican landraces, and used to assess the effects of the crop's spread to North America, and; (iv) US inbred lines were included as descendants of US landraces, and used to assess the effects of modern breeding. Three accessions were chosen as representatives of each of the plant types: "El Cuyotomate," "Talpitita," and "El Rodeo" for Balsas teosinte; Palomero Toluqueño, Chalqueño, and Cacahuacintle for Mexican landraces; Lancaster Sure Crop, Reid Yellow Dent, and Gourdseed for US landraces, and; MO17, B73, and W438 for US inbred lines (Table 2). The teosinte seeds were collected from subtropical lowland locations in Jalisco state, Mexico, whereas the Mexican landraces are grown in the central Mexican highlands. These landraces are ancestral to the selected US landraces through northern Mexican and southwestern US landraces (Merrill et al., 2009; Sánchez, 2011). The US landraces selected for this study are early, parental landraces (Northern Flint and Southern Dent) used to create the early, US Corn Belt inbreds and hybrids (Troyer, 1999; Labate et al., 2003; van Heerwaarden et al., 2012).

Seeds of each accession were germinated in disposable Petri dishes $(150 \times 15 \mathrm{~mm})$ within moistened paper towels for 3 days. Teosinte seeds were initiated $1 \mathrm{~d}$ before maize seeds because they required more time to germinate, and were removed from their fruitcases with a nail clipper. Preliminary germination assays showed no need for seed surface sterilization. After germination, individual seedlings were transplanted to cone-tainers $(4 \times 25 \mathrm{~cm}$ diameter $\times$ length) (Stuewe \& Sons, Tangent, OR, United States) and grown for additional 10-12 days until reaching the V3 stage; water was provided as needed. The cone-tainers were modified with chiffon mesh covering the bottom to prevent escape of Western corn rootworm larvae (preliminary assays not shown here). Growing conditions were $25+2^{\circ} \mathrm{C}, 50 \% \mathrm{RH}$, and 12:12 photoperiod (L:D). The soil used was Baccto ${ }^{\circledR}$ premium potting soil (Michigan Peat Co., Houston, TX, United States), and was sifted (60 mesh strainer) to facilitate subsequent washing of roots (see below). The number of biological replicates per treatment (= seedlings) used for all assays were as follow: Balsas teosinte, $n=25$, Mexican landraces, $n=21$, US landraces, $n=23$, and US inbred lines, $n=23$.

WCR eggs (diapause strain) were provided by USDA-ARSNorth Central Agricultural Research Laboratory (Brookings, $\mathrm{SD}$, United States). Eggs were incubated in Petri dishes at $25 \pm 2{ }^{\circ} \mathrm{C}, \sim 80 \% \mathrm{RH}$ for $12 \pm 1$ days over moistened absorbing paper. Neonate 1st-instar larvae ( $<24 \mathrm{~h}$ after eclosion) were used in all assays.

\section{Host Plant Resistance and Tolerance Assays Plant Resistance}

The aim of this assay was to assess plant resistance through insect and plant performance variables, and compare between pairs of plant types representing the domestication, spread, and breeding transitions in maize. We expected to find decreasing resistance from Balsas teosinte to US inbred lines, manifested as both enhanced WCR larval performance and increased seedling growth.

To assess WCR performance, 10 neonate WCR larvae were placed in each cone-tainer holding a $\sim 15$ day-old seedling (i.e., V3), and allowed to feed for 10 days (Robert et al., 2012b); each seedling was paired with a control seedling of similar size and equal number of leaves in order to estimate seedling growth ratios, as explained below (for sample size see Table 1). After 10 days, the cone-tainer soil was carefully examined and WCR larvae were recovered, counted and stored in 75\% EtOH. Subsequently, each larva's head capsule width was measured to record whether they were in their 1 st, 2 nd, or 3 rd instar (Hammack et al., 2003). These measurements were made with a dissecting stereoscope at $75 \times$ magnification, and equipped with an eyepiece reticle ruler with 100 subdivisions within $10 \mathrm{~mm}$, which had been previously calibrated with a micrometer. Following these measurements, larvae from each cone-tainer were placed in a vial, dried to constant weight ( $\geq 2$ days at 
$65^{\circ} \mathrm{C}$ ), and weighed to obtain average weight per larva per each cone-tainer. Each cone-tainer represented a replicated sample for a plant type.

To assess plant performance, true-leaves 2 and 3 (from the bottom, exclusive of cotyledon) were excised from each seedling, and scanned to measure their surface area using Image ${ }^{\circledR}$ software (Rasband, 2017). After this, the seedling was cut at the base of its stem, placed in a paper envelope (together with the corresponding excised leaves) and dried to constant weight ( $\geq 2$ days at $65^{\circ} \mathrm{C}$ ) (Becker and Meinke, 2008). Seedling roots were rinsed under running water while gently rubbed to remove soil particles, and also dried to constant weight. Stem diameter for each seedling was measured before infestation with WCR, and again prior to harvesting of seedlings, using a digital micrometer (Pittsburgh ${ }^{\circledR}$, Harbor Freight Tools, Camarillo, CA, United States). These measurements were used to assess seedling growth rate and lost seedling growth under WCR herbivory, as explained below.

A multivariate analysis of variance (MANOVA) was applied to evaluate whether resistance differed among the four plant types, indicating effects of domestication, spread, and breeding. The independent variables were 'plant type' (Balsas teosintes, Mexican landraces, US landraces, US inbred lines), and 'accessions' (three per plant as described above in Plants) which were nested within plant type in the MANOVA model. The dependent variables were foliar weight (leaves and stem), leaf surface area, root weight, larval survivorship (number of recovered larvae/10 initial larvae), and average larval weight (per cone-tainer); additionally, growth rate ( $=$ the ratio between seedling stem diameter at days 0 and 10 ), and lost growth (= the ratio between seedling stem diameter of WCR-infested and -non-infested seedlings at day 10 of the assay) were estimated, and included in the analyses. These growth ratios were used to account for known differences in seedling size among plant types (Chinchilla-Ramírez et al., 2017). All data were transformed to $\ln (x)$ prior to analyses; prior to $\ln (x)$ transformation, surface area data were converted to square-root values, and weight data to cubic-root values. A priori contrasts were used for paired comparisons between Balsas teosintes and Mexican landraces, Mexican landraces and US landraces, and US landraces and US inbred lines, using a Sidak-adjusted significance level of $P \leq 0.017$ (Abdi, 2007). Pearson correlations of canonical scores with dependent variables were used to determine the contributions of each dependent variable to the total variation in the canonical axes of MANOVA's centroid plots; Pearson's $r$ values $\geq|0.50|$, and $P \leq 0.05$ were considered significant.

Analysis of variance (ANOVA) was performed for each dependent variable $(P<0.05)$, except for the frequencies of WCR larval instars per plant type. Ratios of plant dependent variables (WCR-infested/non-infested) were used to avoid bias due to phenotypic differences between plant types, as explained above. ANOVA was followed by a priori contrasts to compare between pairs of plant types, as described above. $G$-tests were performed ( $P \leq 0.017$, per Sidak's correction) to test whether the frequency distributions of WCR larval instars varied between pairs of plant types (Abdi, 2007). Additionally, the proportions of 3rd-instar larvae were calculated for each plant type, and used as a proxy for WCR developmental speed; comparisons between plant types were made using a priori contrasts $(P \leq 0.017)$. All statistical analyses were performed using JMP software (SAS Institute Inc, 2018).

\section{Plant Tolerance}

The aim of this assay was to compare plant tolerance between plant types by measuring plant growth in presence and absence of WCR larvae. As before, the comparisons between plant types sought to assess the effects of domestication, spread, and breeding, as described above for Plant resistance. We expected to find increasing tolerance from Balsas teosintes to US inbred lines, manifested as compensation for tissue loss due to feeding by WCR larvae.

The methodology used to assess plant tolerance followed that of an earlier study, with appropriate modifications (ChinchillaRamírez et al., 2017). The plant variables measured for plant resistance (foliar weight, leaf surface area, final stem diameter, and root weight; see above) were measured in treated (with 10 WCR larvae) and control (without WCR larvae) seedlings. Control seedlings were plants similar in size and number of leaves to treated seedlings, so that each treated seedling had a paired, control seedling. MANOVA and Pearson correlations of canonical scores were conducted as described above under Plant Resistance, with some exceptions. Independent variables included 'plant type' (Balsas teosintes, Mexican landraces, US landraces, US inbred lines), 'herbivory' (with and without WCR larvae), 'accessions' (three per plant as described above in plants) nested within plant type, initial stem diameter (at 0 days) (as covariate), and the interaction term 'herbivory $\times$ plant type;' initial stem diameter was included to account for anticipated size different across plant types and accessions (Chinchilla-Ramírez et al., 2017). The dependent variables included were final stem diameter (at 10 days of the assay), foliar weight, leaf surface area, and root weight. Following MANOVA, a priori contrasts between plant types were used to separate multivariate means between pairs of plant types (critical $P \leq 0.017$, per Sidak's correction), as described above. To examine whether seedlings compensated tissue lost to herbivory by WCR, we calculated the mean ratios (=weight of infested seedlings/weight of noninfested seedlings) for each dependent variable, and applied one-sample $t$-tests with the null hypothesis that ratios would not differ from 1 (i.e., $\mathrm{H}_{0}=1$, no loss nor gain of tissue with WCR herbivory); the critical significance level was set to $P \leq 0.012$, per Sidak's correction for four tests (Abdi, 2007). We considered ratio values $<1$ as indicative of under-compensation, values $=1$ of compensation, and $>1$ of over-compensation. Data for these comparisons were transformed to cubic $\operatorname{root}(x)$ values for analyses. All statistical analyses were performed using JMP software (SAS Institute Inc, 2018).

\section{Plant Resistance-Plant Tolerance Trade-Off}

To address the hypothesis that plant resistance trades off with plant tolerance (i.e., are negatively correlated) we conducted correlation analysis of data obtained in the Plant Resistance and Plant Tolerance assays described above. Specifically, we estimated the per-plant accession means for WCR larva weight 
from the Plant resistance assay, and the per-plant accession mean differences in foliar weight between infested (with WCR larvae) and control (without WCR larvae) seedlings in the Plant tolerance assay. We considered larva weight as a proxy for resistance, and the difference in foliar weight as a proxy for tolerance; the difference in foliar weight, rather than the difference in root weight, was used as a tolerance proxy to preclude the effect of lost root tissue due to WCR feeding on any gain of root tissue due to compensation. Mean larva weights were converted to cube$\operatorname{root}(x)$ values, and differences in foliar weight to $\ln (x)$ values to comply with the expectation of normality. Our null hypothesis was that Pearson's correlation coefficient, $r$, was larger than -0.5 , i.e., $r>[-0.5,1]$ at $P \leq 0.05$, indicating the absence of a negative correlation.

\section{DATA AVAILABILITY STATEMENT}

The datasets generated for this study are available on request to the corresponding author.

\section{AUTHOR CONTRIBUTIONS}

AF-P and JB contributed significantly to the conception, design, analysis, interpretation of data, drafted the article and revised it for important intellectual content, conducted statistical analyses

\section{REFERENCES}

Abdi, H. (2007). "The bonferonni and sidak corrections for multiple comparisons," in Encyclopedia of Measurement and Statistics, ed. N. Salkind, (Thousand Oaks, CA: SAGE).

Agrawal, A., Conner, J., and Rasmann, S. (2010). "Tradeoffs and negative correlations in evolutionary ecology," in Evolutionary Ecology: Evolution After Darwin: the First 150 years, eds M. Bell, W. Eanes, D. Futuyama, and J. Levinton, (Sunderland, MA: Sinauer Associates), 243-268.

Agrawal, A. A. (2006). Macroevolution of plant defense strategies. Trends Ecol. Evol. 22, 103-109. doi: 10.1016/j.tree.2006.10.012

Agrawal, A. A., and Fishbein, M. (2008). Phylogenetic escalation and decline of plant defense strategies. Proc. Natl. Acad. Sci. U.S.A. 105, 10057-10060. doi: 10.1073/pnas.0802368105

Agrawal, A. A., Hastings, A. P., Johnson, M. T., Maron, J. L., and Salminen, J. P. (2012). Insect herbivores drive real-time ecological and evolutionary change in plant populations. Science 338, 113-116. doi: 10.1126/science.122 5977

Baker, H. G. (1972). Human influences on plant evolution. Econ. Bot. 26, 32-43. doi: $10.1007 / \mathrm{bf02862259}$

Barton, K. E., and Hanley, M. E. (2013). Seedling-herbivore interactions: insights into plant defence and regeneration patterns. Ann. Bot. 112, 643-650. doi: $10.1093 / \mathrm{aob} / \mathrm{mct} 139$

Bazzaz, F. A., Chiariello, N. R., Coley, P. D., and Pitelka, L. F. (1987). Allocating resources to reproduction and defense. Bioscience 37, 58-67. doi: 10.2307/ 1310178

Becker, S. C., and Meinke, L. J. (2008). A technique to morphologically differentiate larvae of Diabrotica virgifera virgifera and D. barberi (Coleoptera: Chrysomelidae). J. Kans. Entomol. Soc. 81, 77-79. doi: 10.2317/jkes705-02.1

Bellota, E., Medina, R. F., and Bernal, J. S. (2013). Physical leaf defenses - altered by Zea life-history evolution, domestication, and breeding - mediate oviposition preference of a specialist leafhopper. Entomol. Exp. Appl. 149, 185-195. doi: 10.1111/eea.12122 and interpretation, and approved the final version to be published. AF-P performed all the experiments and collected the data.

\section{FUNDING}

This study was supported in part by CONACyT and INIFAP (both Mexico) funding to AF-P (CONACyT scholarship \#382690), as well as TAMU-CONACyT [Characterization of Resistance to Root-And Foliage-Feeding Insects in Maize Breeding Lines, Landraces and Wild Ancestors, Project 2014-024(S)] and USDA Hatch (TEX07234) funding to JB.

\section{ACKNOWLEDGMENTS}

We are grateful to M. J. Kolomiets and his laboratory (Texas A\&M University, College Station), who kindly provided technical support and maize seed. Dr. Mark Millard (USDA NPGS, Ames, IA, United States) provided Mo17, and Mexican and US maize landrace seed, and Chad Nielson (USDA ARS, North Central Agricultural Research Laboratory, Brookings, SD, United States) provided Western corn rootworm eggs. M. J. Kolomiets, R. F. Medina, and K. Zhu-Salzman (all Texas A\&M University, College Station) helped us improve an earlier version of the manuscript.

Bernal, J. S., Davila-Flores, A. M., Medina, R. F., Chen, Y. H., Harrison, K. E., and Berrier, K. A. (2017). Did maize domestication and early spread mediate the population genetics of corn leafhopper? Insect Sci. 26, 569-586. doi: 10.1111/ 1744-7917.12555

Bernal, J. S., and Medina, R. F. (2018). Agriculture sows pests: how crop domestication, host shifts, and agricultural intensification can create insect pests from herbivores. Curr. Opin. Insect Sci. 26, 76-81. doi: 10.1016/j.cois.2018. 01.008

Bernal, J. S., Melancon, J. E., and Zhu-Salzman, K. (2015). Clear advantages for fall armyworm larvae from feeding on maize relative to its ancestor Balsas teosinte may not be reflected in their mother's host choice. Entomol. Exp. Appl. 155, 206-217. doi: 10.1111/eea.12299

Bernklau, E. J., and Bjostad, L. B. (2008). Identification of feeding stimulants in corn roots for western corn rootworm (Coleoptera: Chrysomelidae) larvae. J. Econ. Entomol. 101, 341-351. doi: 10.1093/jee/101.2.341

Blossey, B., and Notzold, R. (1995). Evolution of increased competitive ability in invasive nonindigenous plants: a hypothesis. Br. Ecol. Soc. 83, 887-889.

Boege, K., and Marquis, R. J. (2005). Facing herbivory as you grow up: the ontogeny of resistance in plants. Trends Ecol. Evol. 20, 441-448. doi: 10.1016/j.tree.2005. 05.001

Branson, T. F., and Krysan, J. L. (1981). Feeding and oviposition behavior and life cycle strategies of Diabrotica: an evolutionary view with implications for pest management. Environ. Entomol. 10, 826-831. doi: 10.1093/ee/10.6.826

Branson, T. F., and Ortman, E. E. (1967). Host range of larvae of the western corn rootworm. J. Econ. Entomol. 60, 201-203. doi: 10.1093/jee/60.1.201

Branson, T. F., and Ortman, E. E. (1970). The host range of larvae of the western corn rootworm: further studies. J. Econ. Entomol. 63, 800-803. doi: 10.1093/jee/ 63.3.800

Buckler, E. S. I., and Stevens, N. M. (2006). "Maize origins, domestication, and selection," in Darwin's Harvest, New Approaches to the Origins, Evolution, and Conservation of Crops, eds T. J. Motley, Z. Nyree, and H. Cross, (New York, NY: Columbia University Press).

Chacon-Fuentes, M., Parra, L., Rodriguez-Saona, C., Seguel, I., Ceballos, R., and Quiroz, A. (2015). Domestication in murtilla (Ugni molinae) reduced defensive 
flavonol levels but increased resistance against a native herbivorous insect. Environ. Entomol. 44, 627-637. doi: 10.1093/ee/nvv040

Chapman, R. F. (2003). Contact chemoreception in feeding by phytophagous insects. Annu. Rev. Entomol. 48, 455-484. doi: 10.1146/annurev.ento.48.091801. 112629

Chen, Y. H. (2016). Crop domestication, global human-mediated migration, and the unresolved role of geography in pest control. Elementa 4:106. doi: 10.12952/ journal.elementa.000106

Chen, Y. H., Gols, R., and Benrey, B. (2015a). Crop domestication and its impact on naturally selected trophic interactions. Annu. Rev. Entomol. 60, 35-58. doi: 10.1146/annurev-ento-010814-020601

Chen, Y. H., Gols, R., Stratton, C. A., Brevik, K. A., and Benrey, B. (2015b). Complex tritrophic interactions in response to crop domestication: predictions from the wild. Entomol. Exp. Appl. 157, 40-59. doi: 10.1111/eea.12344

Chen, Y. H., and Schoville, S. D. (2018). Editorial overview: ecology: ecological adaptation in agroecosystems: novel opportunities to integrate evolutionary biology and agricultural entomology. Curr. Opin. Insect Sci. 26, iv-viii. doi: 10.1016/j.cois.2018.03.003

Chinchilla-Ramírez, M., Borrego, E. J., DeWitt, T. J., Kolomiets, M. V., and Bernal, J. S. (2017). Maize seedling morphology and defence hormone profiles, but not herbivory tolerance, were mediated by domestication and modern breeding. Ann. Appl. Biol. 170, 315-332. doi: 10.1111/aab.12331

Da Costa, C. P., and Jones, C. M. (1971). Cucumber beetle resistance and mite susceptibility controlled by the bitter gene in Cucumis sativus L. Science 172, 1145-1146. doi: 10.1126/science.172.3988.1145

da Fonseca, R. R., Smith, B. D., Wales, N., Cappellini, E., Skoglund, P., Fumagalli, M., et al. (2015). The origin and evolution of maize in the Southwestern United States. Nat. Plants 1:14003. doi: 10.1038/nplants.2014.3

Dávila-Flores, A. M., DeWitt, T. J., and Bernal, J. S. (2013). Facilitated by nature and agriculture: performance of a specialist herbivore improves with host-plant life history evolution, domestication, and breeding. Oecologia 173, 1425-1437. doi: 10.1007/s00442-013-2728-2

de Lange, E. S., Balmer, D., Mauch-Mani, B., and Turlings, T. C. J. (2014). Insect and pathogen attack and resistance in maize and its wild ancestors, the teosintes. New Phytol. 204, 329-341. doi: 10.1111/nph.13005

Dorweiler, J., Stec, A., Kermicle, J., and Doebley, J. (1993). Teosinte glume architecture 1: a genetic locus controlling a key step in maize evolution. Science 262, 233-235. doi: 10.1126/science.262.5131.233

Duvick, D. N. (2005). "The contribution of breeding to yield advances in maize (Zea mays L.)," in Advances in Agronomy, ed. D. L. Sparks, (San Diego, CA: Elsevier Academic Press), 83-145. doi: 10.1016/s0065-2113(05)86002-x

Erb, M., Balmer, D., De Lange, E. S., Von Merey, G., Planchamp, C., Robert, C. A., et al. (2011). Synergies and trade-offs between insect and pathogen resistance in maize leaves and roots. Plant Cell Environ. 34, 1088-1103. doi: 10.1111/j.13653040.2011.02307.x

Flint-Garcia, S. A., Bodnar, A. L., and Scott, M. P. (2009). Wide variability in kernel composition, seed characteristics, and zein profiles among diverse maize inbreds, landraces, and teosinte. Theory Appl. Genet. 119, 1129-1142. doi: 10. 1007/s00122-009-1115-1

Gerdes, J. T., Behr, C. F., Coors, J. G., and Tracy, W. F. (1993). Compilation of North American Maize Breeding Germplasm. Fitchburg, WI: Crop Science Society of America.

Gols, R., Wagenaar, R., Bukovinszky, T., van Dam, N. M., Dicke, M., Bullock, J. M., et al. (2008). Genetic variation in defense chemistry in wild cabbages affects herbivores and their endoparasitoids. Ecology 89, 1616-1626. doi: 10.1890/070873.1

Gray, M. E., Sappington, T. W., Miller, N. J., Moeser, J., and Bohn, M. O. (2009). Adaptation and invasiveness of western corn rootworm: intensifying research on a worsening pest. Annu. Rev. Entomol. 54, 303-321. doi: 10.1146/annurev. ento.54.110807.090434

Hahn, P. G., and Maron, J. L. (2016). A framework for predicting intraspecific variation in plant defense. Trends Ecol. Evol. 31, 646-656. doi: 10.1016/j.tree. 2016.05.007

Hammack, L., Ellsbury, M. M., Roehrdanz, R. L., and Pikul, J. L. (2003). Larval sampling and instar determination in field populations of Northern and Western Corn Rootworm (Coleoptera: Chrysomelidae). J. Econ. Entomol. 96, 1153-1159. doi: 10.1093/jee/96.4.1153
Herms, D. A., and Mattson, W. J. (1992). The dilemma of plants: to grow or defend. Q. Rev. Biol. 67, 283-335. doi: 10.1086/417659

Howe, W. L., Sanborn, J. R., and Rhodes, A. M. (1976). Western Corn Rootworm 1 Adult and Spotted Cucumber Beetle 1 Associations with Cucurbita and Cucurbitacins 2. Environ. Entomol. 5, 1043-1048. doi: 10.1093/ee/5.6.1043

Ivezić, M., Raspudić, E., Brmež, M., Majić, I., Brkić, I., Tollefson, J. J., et al. (2009). A review of resistance breeding options targeting western corn rootworm (Diabrotica virgifera virgifera LeConte). Agric. For. Entomol. 11, 307-311. doi: 10.1111/j.1461-9563.2009.00434.x

Kistler, L., Maezumi, S. Y., Gregorio de Souza, J., Przelomska, N. A. S., Malaquias Costa, F., Smith, O., et al. (2018). Multiproxy evidence highlights a complex evolutionary legacy of maize in South America. Science 362:1309. doi: 10.1126/ science.aav0207

Kutka, F. (2011). Open-Pollinated vs. Hybrid Maize Cultivars. Sustainability 3, 1531-1554. doi: 10.3390/su3091531

Labate, J. A., Lamkey, K. R., Mitchell, S. E., Kresovich, S., Sullivan, H., and Smith, J. S. C. (2003). Molecular and historical aspects of corn belt dent diversity. Crop Sci. 43, 80-91.

Lombaert, E., Ciosi, M., Miller, N. J., Sappington, T. W., Blin, A., and Guillemaud, T. (2017). Colonization history of the western corn rootworm (Diabrotica virgifera virgifera) in North America: insights from random forest ABC using microsatellite data. Biol. Invasions 20, 665-677. doi: 10.1007/s10530-0171566-2

Maag, D., Erb, M., Köllner, T. G., and Gershenzon, J. (2015). Defensive weapons and defense signals in plants: some metabolites serve both roles. Bioessays 37 , 167-174. doi: 10.1002/bies.201400124

Macfadyen, S., and Bohan, D. A. (2010). Crop domestication and the disruption of species interactions. Basic Appl. Ecol. 11, 116-125. doi: 10.1016/j.baae.2009.11. 008

Matsuoka, Y., Vigouroux, Y., Goodman, M. M., Sanchez, G. J., Buckler, E., and Doebley, J. (2002). A single domestication for maize shown by multilocus microsatellite genotyping. Proc. Natl. Acad. Sci. U.S.A. 99, 6080-6084. doi: 10.1073/pnas.052125199

Medina, R. F., Reyna, S. M., and Bernal, J. S. (2012). Population genetic structure of a specialist leafhopper on Zea: likely anthropogenic and ecological determinants of gene flow. Entomol. Exp. Appl. 142, 223-235. doi: 10.1111/j.1570-7458.2012. 01220.x

Meihls, L. N., Huynh, M. P., Ludwick, D. C., Coudron, T. A., French, B. W., Shelby, K. S., et al. (2018). Comparison of six artificial diets for western corn rootworm bioassays and rearing. J. Econ. Entomol. 111, 2727-2733. doi: 10. 1093/jee/toy268

Merrill, W. L., Hard, R. J., Mabry, J. B., Fritz, G. J., Adams, K. R., Roney, J. R., et al. (2009). The diffusion of maize to the southwestern United States and its impact. Proc. Natl. Acad. Sci. U.S.A. 106, 21019-21026. doi: 10.1073/pnas.090607 5106

Mesa, J. M., Scholes, D. R., Juvik, J. A., and Paige, K. N. (2017). Molecular constraints on resistance-tolerance trade-offs. Ecology 98, 2528-2537. doi: 10. 1002/ecy.1948

Meyer, R. S., DuVal, A. E., and Jensen, H. R. (2012). Patterns and processes in crop domestication: an historical review and quantitative analysis of 203 global food crops. New Phytol. 196, 29-48. doi: 10.1111/j.1469-8137.2012.04253.x

Nault, L. R. (1990). Evolution of an insect pest: maize and the corn leafhopper, a case study. Maydica 35, 165-175.

Painter, R. H. (1951). Insect Resistance in Crop Plants. Lawrence, KS: University Press of Kansas.

Palladino, P., and Fitzgerald, D. (1996). Entomology, ecology, and agriculture: the making of scientific careers in North America, 1885-1985. Technol. Culture 39, 584-585. doi: 10.1353/tech.1998.0029

Pearse, I. S., Aguilar, J., Schroder, J., and Strauss, S. Y. (2017). Macroevolutionary constraints to tolerance: trade-offs with drought tolerance and phenology, but not resistance. Ecology 98, 2758-2772. doi: 10.1002/ecy.1995

Perkins, J. H. (1982). Insects, Experts, and the Insecticide Crisis: The Quest for New Pest Management Strategies. New York, NY: Plenum Press.

Pujol, B., Muhlen, G., Garwood, N., Horoszowski, Y., Douzery, E. J., and McKey, D. (2005). Evolution under domestication: contrasting functional morphology of seedlings in domesticated cassava and its closest wild relatives. New Phytol. 166, 305-318. doi: 10.1111/j.1469-8137.2004.01295.x 
Qu, W., Robert, C. A., Erb, M., Hibbard, B. E., Paven, M., Gleede, T., et al. (2016). Dynamic precision phenotyping reveals mechanism of crop tolerance to root herbivory. Plant Physiol. 172, 776-788. doi: 10.1104/pp.16.00735

Rasband, W. (2017). ImageJ. Available at: https://imagej.nih.gov/ij/index.html (accessed June 19, 2017).

Rasmann, S., Köllner, T. G., Degenhardt, J., Hiltpold, I., Toepfer, S., Kuhlmann, U., et al. (2005). Recruitment of entomopathogenic nematodes by insect-damaged maize roots. Nature 434, 732-737. doi: 10.1038/nature03451

Richardson, J. T. E. (2011). Eta squared and partial eta squared as measures of effect size in educational research. Educ. Res. Rev. 6, 135-147. doi: 10.1016/j.edurev. 2010.12.001

Robert, C. A. M., Erb, M., Hibbard, B. E., Wade French, B., Zwahlen, C., Turlings, T. C. J., et al. (2012b). A specialist root herbivore reduces plant resistance and uses an induced plant volatile to aggregate in a density-dependent manner. Funct. Ecol. 26, 1429-1440. doi: 10.1111/j.1365-2435.2012.02030.x

Robert, C. A. M., Veyrat, N., Glauser, G., Marti, G., Doyen, G. R., Villard, N., et al. (2012a). A specialist root herbivore exploits defensive metabolites to locate nutritious tissues. Ecol. Lett. 15, 55-64. doi: 10.1111/j.1461-0248.2011.01708.x

Robert, C. A. M., Zhang, X., Machado, R. A., Schirmer, S., Lori, M., Mateo, P., et al. (2017). Sequestration and activation of plant toxins protect the western corn rootworm from enemies at multiple trophic levels. eLife 6:e29307. doi: 10.7554/eLife.29307

Rodriguez-Saona, C., Vorsa, N., Singh, A. P., Johnson-Cicalese, J., Szendrei, Z., Mescher, M. C., et al. (2011). Tracing the history of plant traits under domestication in cranberries: potential consequences on anti-herbivore defences. J. Exp. Bot. 62, 2633-2644. doi: 10.1093/jxb/erq466

Rosenthal, J. P., and Dirzo, R. (1997). Effects of life history, domestication and agronomic selection on plant defence against insects: evidence from maize and wild relatives. Evol. Ecol. 11, 337-355. doi: 10.1023/a:1018420504439

Sánchez, G. J. J. (2011). Diversidad del Maíz y Teocintle. Informe Preparado para el Proyecto: Recopilación, Generación, Actualización y Análisis de Información Acerca de la Diversidad Genética de Maíces y sus Parientes Silvestres en México. Mexico: CONABIO.

SAS Institute Inc (2018). "JMP" Pro 14.0.0 ed. Cary, NC: SAS.

Schoonhoven, L. M., van Loon, J. J. A., and Dicke, M. (2005). Insect-Plant Biology. New York, NY: Oxford University Press.

Simms, E. L. (2000). Defining tolerance as a norm of reaction. Evol. Ecol. 14, 563-570. doi: 10.1023/A:1010956716539

Smith, B. D. (2011). General patterns of niche construction and the management of 'wild' plant and animal resources by small-scale pre-industrial societies. Philos. Trans. R. Soc. B Biol. Sci. 366, 836-848. doi: 10.1098/rstb.2010.0253

Smith, B. D., Boivin, N., Petraglia, M., and Crassard, R. (2017). "Tracing the initial diffusion of maize in North America," in Human Dispersal and Species Movement, eds N. Boivin, R. Crassard, and M. Petraglia, (Cambridge: Cambridge University Press), 332-348. doi: 10.1017/9781316686942.014

Stamp, N. (2003). Out of the quagmire of plant defense hypotheses. Q. Rev. Biol. 78, 23-55. doi: $10.1086 / 367580$

Stout, M. J. (2013). Reevaluating the conceptual framework for applied research on host-plant resistance. Insect Sci. 20, 263-272. doi: 10.1111/1744-7917.12011

Strauss, S. Y., and Agrawal, A. A. (1999). The ecology and evolution of plant tolerance to herbivory. Tree 14, 179-185. doi: 10.1016/s0169-5347(98)01 576-6

Strauss, S. Y., Rudgers, J. A., Lau, J. A., and Irwin, R. E. (2002). Direct and ecological cost of resistance to herbivory. Trends Ecol. Evol. 17, 278-285. doi: 10.1016/ s0169-5347(02)02483-7

Swarts, K., Gutaker, R. M., Benz, B., Blake, M., Bukowski, R., Holland, J., et al. (2017). Genomic estimation of complex traits reveals ancient maize adaptation to temperate North America. Science 357, 512-515. doi: 10.1126/science. aam 9425

Szczepaniec, A., Widney, S. E., Bernal, J. S., and Eubanks, M. D. (2013). Higher expression of induced defenses in teosintes (Zea spp.) is correlated with greater resistance to fall armyworm, Spodoptera frugiperda. Entomol. Exp. Appl. 146, 242-251. doi: 10.1111/eea.12014

Troyer, A. F. (1999). Background of U.S. Hybrid Corn. Crop Sci. 39, 601-626.

Turcotte, M. M., Araki, H., Karp, D. S., Poveda, K., and Whitehead, S. R. (2017). The eco-evolutionary impacts of domestication and agricultural practices on wild species. Philos. Trans. R. Soc. B Biol. Sci. 372:20160033. doi: 10.1098/rstb. 2016.0033

Turcotte, M. M., Turley, N. E., and Johnson, M. T. (2014). The impact of domestication on resistance to two generalist herbivores across 29 independent domestication events. New Phytol. 204, 671-681. doi: 10.1111/nph.12935

van Heerwaarden, J., Hufford, M. B., and Ross-Ibarra, J. (2012). Historical genomics of North American maize. Proc. Natl. Acad. Sci. U.S.A. 109, 1242012425. doi: 10.1073/pnas.1209275109

Wang, X., Chen, Q., Wu, Y., Lemmon, Z. H., Xu, G., Huang, C., et al. (2018). Genome-wide analysis of transcriptional variability in a large maizeteosinte population. Mol. Plant 11, 443-459. doi: 10.1016/j.molp.2017. 12.011

Wesseler, J., and Fall, E. H. (2010). Potential damage costs of Diabrotica virgifera virgifera infestation in Europe - the 'no control' scenario. J. Appl. Entomol. 134, 385-394. doi: 10.1111/j.1439-0418.2010.01510.x

Whitehead, S. R., Turcotte, M. M., and Poveda, K. (2017). Domestication impacts on plant-herbivore interactions: a meta-analysis. Philos. Trans. R. Soc. B Biol. Sci. 372:20160034. doi: 10.1098/rstb.2016.0034

Wright, S. I., Bi, I. V., Schroeder, S. G., Yamasaki, M., Doebley, J., McMullen, M. D., et al. (2005). The effects of artificial selection on the maize genome. Science 308, 1310-1314. doi: 10.1126/science.1107891

Zangerl, A. R., and Berenbaum, M. R. (2005). Increase in toxicity of an invasive weed after reassociation with its coevolved herbivore. Proc. Natl. Acad. Sci. U.S.A. 102, 15529-15532. doi: 10.1073/pnas.0507805102

Zhou, S., Lou, Y. R., Tzin, V., and Jander, G. (2015). Alteration of plant primary metabolism in response to insect herbivory. Plant Physiol. 169, 1488-1498. doi: 10.1104/pp.15.01405

Zou, J., Rogers, W. E., and Siemann, E. (2007). Differences in morphological and physiological traits between native and invasive populations of Sapium sebiferum. Funct. Ecol. 21, 721-730. doi: 10.1111/j.1365-2435.2007.01 298.x

Zust, T., and Agrawal, A. A. (2017). Trade-offs between plant growth and defense against insect herbivory: an emerging mechanistic synthesis. Annu. Rev. Plant Biol. 68, 513-534. doi: 10.1146/annurev-arplant-042916-040856

Züst, T., Heichinger, C., Grossniklaus, U., Harrington, R., Kliebenstein, D. J., and Turnbull, L. A. (2012). Natural enemies drive geographic variation in plant defenses. Science 338, 116-119. doi: 10.5061/dryad.6331s

Conflict of Interest: The authors declare that the research was conducted in the absence of any commercial or financial relationships that could be construed as a potential conflict of interest.

Copyright (c) 2020 Fontes-Puebla and Bernal. This is an open-access article distributed under the terms of the Creative Commons Attribution License (CC BY). The use, distribution or reproduction in other forums is permitted, provided the original author(s) and the copyright owner(s) are credited and that the original publication in this journal is cited, in accordance with accepted academic practice. No use, distribution or reproduction is permitted which does not comply with these terms. 